\title{
MUJER, HOGAR Y ECONOMÍA FAMILIAR. DESIGUALDAD Y ADAPTACIÓN EN LA SIERRA DE ALCARAZ A MEDIADOS DEL SIGLO XVIII
}

por

\section{FRANCISCO García GONZALEZ}

Universidad de Castilla-La Mancha

RESUMEN: Dentro de la multiplicidad de perspectivas desde las que se puede abordar el tema de la mujer, a lo largo del presente trabajo sólo se ha adoptado como unidad de análisis a las mujeres cabezas de familia. Tomando como base una zona de montaña de la España meridional como era la Sierra de Alcaraz a mediados del siglo XVH, gracias a un soporte documental como el Catastro del Marqués de la Ensenada y su interrelación nominativa con otras fuentes (sobre todo notariales), se ha llevado a cabo una aproximación a la realidad demográfica, económica y social de dichas mujeres. Después de cuantificar la entidad del fenómeno y las caracteristicas de sus agregados y economias domésticas, se ha contstatado y evaluado la desigualdad existente entre sus unidades familiares y la importancia que en su determinación tenían tanto status y riqueza como prácticas de herencia y ciclo de vida. Por tiltimo, en función de ello, se han analizado las distintas medidas estratégicas y adaptativas adoptadas, bien para evitar caer en la indigencia, bien para seguir perpetuando y reproduciendo posición y patrimonio.

Palabras clave. Edad Moderna, Siglo xvir, España, Castilla, Sierra de Alcaraz, Mujer, Hogar, Familia, Ciclo vital, Economía doméstica, Explotación campesina, Estructura de la propiedad, Sistema de herencia, Estrategia familiar.

1 Este trabajo se incluye dentro del proyecto Nuevas perspectivas sobre la estructura social en la España del Antiguo Régimen: Ciclo de vida, estrategia matrimonial y reproducción sociocultural, financiado por la Dirección General de Investigación Científica y Técnica (PB94-1137) y dirigido por el profesor don Francisco Chacón Jiménez. Una primera versión del mismo fue presentada al IV Congreso de la Asociación de Demografía Histórica celebrado entre los días 20 y 22 de Septiembre del año 1995 en Bilbao y San Sebastián (sesión Economía y Demografia de la Familia). 
ABSTRACT: Woman, Household and Family Economy. Inequality and Adaptation in the Alcaraz Mountains in Mid-Eighteenth Century. Within the multiplicity of perspectives from which the topic of women can be studied, only women head of the family hare been adopted as case of analysis throughout this paper article. With the main enphasis upon mountainous area in Southern Spain, the Alcaraz Mountains, in mid-Eighteenth century, thanks to the documentary support provided by Catastro del Marqués de la Ensenada and its nominative relationships with other sources (mostly notarial), we hare attempted an approximative focus on those women's demographic, economic and social reality. After assessing the entity of this phenomenon and the characteristics of its aggregated and domestic economies, we hare verified and evaluated the inequality extant in their family units and the importance which both status and wealth, as practices of inheritance and life cycle (vital cycle), had in their configuration. Last brit not learst related to what has been already established, we hare analyzed the different strategic and adaptative measures adopted, either to avoid falling into indigence (poverty), or to go on perpetuating and reproducing position and patrimony.

KEY words: Modern Age, Eighteenth Century, Spain, Castille, Alcaraz Mountains, Women, Household, Family, Life cycle, Domestic (Family) economy, Peasant exploitation, Property Structure, Inheritance system, Family Strategy.

Dentro de la multiplicidad de perspectivas desde las que se puede abordar el tema de la mujer, a lo largo del presente trabajo sólo se adoptará como unidad de análisis la mujer cabeza de familia, una realidad, como ya señalara hace algunos años Fauve-Chamoux ${ }^{2}$, en absoluto marginal en las sociedades del pasado. Nuestro interés, pues, se centrará en aquéllas mujeres cuya condición venía definida directamente por su estado matrimonial: viudedad o celibato eran las principales causas por las que una mujer podía acceder a la jefatura del hogar en el Antiguo Régimen, aunque podía deberse también a la ausencia del cónyuge (o ruptura del matrimonio por razones no biológicas como emigración, prisión, etc) e incluso derivarse de casos de paternidad no reconocida.

Sin embargo, delimitado nuestro objeto de estudio, la cuestión es cómo diferenciarlo socialmente, cómo discernir sus desigualdades internas cuando las fuentes más comunes utilizadas para ello (censos, padrones y otras listas nominativas) no permiten alcanzar tal objetivo. En principio los datos referidos al tipo de actividad desempeñada, a la ocupación socio-profesional, serían indispensables para situar a los individuos dentro de la estructura social, pero esto no siempre ocurre para las mujeres, para las que en todo caso sólo se precisa su condición de pobre o su condición derivada del estado civil. Desgra-

2 (1981:213). Artículo incluido dentro de un monográfico que la revista Annales de Démographie Historique dedicó a demografia histórica y condición femenina, donde se abordaron temas como la mortalidad diferencial de las mujeres, la elección del cónyuge o la mujer sola. Sobre ta forma de abordar este último aspecto en la pasada década véanse también los números monográficos de las revistas Journal of Family History (1984) o Memoria (1987).

Hispania, LVIJ/1, núm. 195 (1997) 115-145 
ciadamente un claro ejemplo de ello lo encontramos en el espacio elegido para nuestro trabajo, la comarca de la Sierra de Alcaraz ${ }^{3}$, con una de las fuentes más ricas para el estudio del hogar y de la familia en el Antiguo Régimen como son los llamados Libros de lo Personal (o de Familias) del Catastro del Marqués de la Ensenada (1753): sólo en torno a un 10 por ciento de las mujeres cabezas de casa tenían indicada algún tipo de actividad o venían calificadas como pobres, lo que es inadmisible 4 .

Pero aún así, si hubiéramos contado con tales referencias, como han señalado M. Gribaudi y A. Blum ${ }^{5}$, no debemos olvidar que una misma denominación profesional puede recubrir significaciones sociales muy diferentes. En este sentido, no es extraño que incluso las propias categorías o nomenclaturas utilizadas como herramientas de análisis y descripción se hayan convertido en objetos de historia en sí mismas ${ }^{6}$. En concreto, con respecto al concepto "pobre», Stuart Woolf 7 ya señalaba hace algunos años que con demasiada facilidad los historiadores se equivocan al tomar una continuidad terminológica de las categorías por una continuidad sustancial de la realidad. $\mathrm{Y}$ esto mismo cabe decir de la ecuación viuda-pobre, una relación que está presente en la mayor parte de los empadronamientos de base fiscal desde el siglo xvi. Por desgracia, al discurso oficial concerniente al conocimiento de la población hay que unir una serie de tópicos referidos al lugar que ocupaban las mujeres en la vida familiar y laboral y, en general, en el conjunto de la sociedad, que acabarian por asociarlas con una determinada "manera de ser", con unos determinados atributos y rasgos que justificaban unos específicos padrones de comportamiento y que, en definitiva, terminarian por afianzar una visión excesivamente homogénea y uniforme de su situación ${ }^{8}$.

3 Continuación del macizo formado por las cordilleras subbéticas andaluzas y zona de transición con la Meseta castellana, la comarca de la Sierra de Alcaraz, hoy dentro de la actual provincia de Albacete, a mediados del siglo xviı accidentaba la parte suroriental de la antigua provincia de La Mancha. Desde el punto de vista jurisdiccional se componía de dos estructuras totalmente contrapuestas: la zona de realengo correspondiente a la propia ciudad de Alcaraz más sus doce aldeas dependientes (que era el espacio más extenso y poblado), y la del Señorio de las Cinco Villas, que incluía sólo a cinco pequeños núcleos serranos.

439 casos de 366 mujeres. Pero es más, para todos los agregados correspondientes a la jurisdicción de Alcaraz, que en realidad constituian la mayor parte de los contabilizados para toda la comarca, incluso para las mismas esposas de los cabezas de familia varones ni siquiera se nos indica su edad y mucho menos si ejercían algún tipo de actividad laboral. Un caso en cierto modo diferente siguiendo la misma fuente lo encontramos por ejemplo en Granada (CASEY, J.-VINCENT, B., 1987) o en Oviedo (López JGLESIAS, F. A., 1987), donde la información facilitada ha permitido realizar una primera aproximación a la actividad laboral de las mujeres.

5 (1990:1398).

6 Chartier, R., (1993a).

7 (1989:17).

8 Para una interesante reflexión sobre los tópicos relativos a la mujer en el Antiguo Régimen véase por ejemplo CARBONELL, M., (1990:125-129). Por otro lado, no es raro encontrar estudios donde las conclusiones obtenidas para las mujeres se fundamentan en el hecho de analizar a viudas y solteras, dentro de su heterogeneidad, como una categoria más dentro de la clasificación socio-profesional. Este problema para el caso de] Catastro del Marqués de la Ensenada ya lo apuntaban CASEY, J.-VINCENT, B., (1987:176). 
Con objeto de no reducir la complejidad social a unos estereotipos muy marcados y tratar de aproximarnos a la realidad de las mujeres cabezas de familia (y en especial de las viudas por representar su mayor número), nos proponemos reconstruir el perfil del hogar y de las economías domésticas dirigidas por una mujer. Luego marcaremos sus diferencias y por último intentaremos aproximarnos a las causas de sus desigualdades y, en consecuencia, a las múltiples formas y estrategias de supervivencia o reproducción adoptadas en función de su distinta situación.

Para conseguir nuestros objetivos ha sido imprescindible superar las dificultades derivadas del uso exclusivo de fuentes como los Libros de Personal (o de familias) del Catastro de la Ensenado u otras listas nominativas de habitantes. Así, gracias al cruce nominativo de dichos libros con los de la propiedad (o Libros de lo Real, que junto con aquéllos componen las denominadas Respuestas Particulares del mencionado Catastro) y a la informatización de sus datos hemos podido plantear la cuestión desde una perspectiva diferencial atendiendo tanto a los factores estructurales derivados de la propiedad como de la edad. Ello nos ha permitido, por otro lado, preguntarnos hasta qué punto los hogares encabezados por una mujer se caracterizaban por una mayor precariedad y por lo tanto si se puede colegir que aquéllos se empobrecían cuando pasaban a estar regidos por las mismas. De esta forma, como una primera etapa de nuestro análisis, presentaremos los aspectos más cuantitativos del fenómeno de las mujeres cabezas de familia. Una primera etapa evidentemente descriptiva pero, a nuestro juicio, imprescindible para proyectar, también desde el cruce nominativo, toda una serie de informaciones procedentes de otras fuentes que hacían referencia a distintos casos y familias a lo largo del tiempo y que nos han permitido apuntar y comprender algunos comportamientos 9 . Trataremos de superar así un análisis excesivamente estático del problema ${ }^{10}$ para preocuparnos al contrario por su vertiente de proceso, tanto de pauperización como de mantenimiento o incremento del status y del patrimonio, y por los mecanismos y estrategias seguidos, bien para evitar caer en la indigencia y conseguir un cierto equilibrio dentro de lo inestable de la subsistencia en el Antiguo Régimen, o bien para seguir perpetuando y reproduciendo la desigualdad como algo intrínseco al sistema social "'.

9 Entre estas fuentes están las mismas Comprobaciones del Catastro de la Ensenada realizadas ocho años después, algunos padrones y libros de matricula, dotes, testamentos y otra variada documentación notarial.

$10 \mathrm{Ni}$ el agregado doméstico se abordará como una mera unidad residencial al preocuparnos también por los lazos que se establecen con el exterior ni la mujer será estudiada sólo en el momento del matrimonio y en relación a la dote y al sistema de transmisión de la propiedad.

1 No en vano autores como CHACón JIMĖNEZ, F., (1987:168) no dudan en calificar a la mujer como la bóveda del edificio social al ser protagonista de las estrategias puestas en práctica por los grupos de poder.

Hispania, LVI//, ม̉m. 195 (1997) II5-145 


\section{I. "CADA UNO EN SU CASA" O LA CARACTERIZACION DEMOGRAFICA DEL HOGAR}

En el Antiguo Régimen, la desigual esperanza de vida de los hombres y de las mujeres (cuyo reflejo indirectamente puede observarse en la desequilibrada composición por sexo de la población en edades avanzadas favorable a la mujer) así como la diferencia de edad de acceso al matrimonio (por lo general de tres años en esta comarca según los datos del Censo de Floridablanca) conllevaba que, con más frecuencia que entre los hombres, muchas mujeres quedaran solas, con o sin cargas familiares, durante un tiempo. A ello contribuía también la mayor tendencia, refrendada por la costumbre, de que los varones volvieran de nuevo a contraer matrimonio dando lugar, evidentemente, a un menor número de hogares de viudos, aunque en esta zona, desde los libros parroquiales sabemos que a lo largo del siglo xviII el porcentaje de viudas que reingresaban en el mercado matrimonial no era nada despreciable: más del 41 por ciento del total de los viudo/as que volvían a casarse eran mujeres.

Con todo, las elevadas tasas de mortalidad que caracterizaban a esta zona se traducian en la existencia de numerosos hogares compuestos por un viudo o una viuda, solos o con sus hijos tras la muerte de sus cónyuges, o jóvenes solitarios/as o con sus hermanos $\mathbf{u}$ otros parientes encabezando sus hogares al desaparecer sus padres. De hecho, de 2313 hogares contababilizados en la comarca, las mujeres encabezaban 366 o el 15,8 por ciento de los agregados. De ellos, como puede verse en el Cuadro I, 29 correspondían a mujeres solteras y 3 con el marido ausente (más otro caso del que desconocemos su estado civil), por lo que dicho porcentaje en realidad reflejaba más bien el peso y la relevancia social de las viudas dentro de estas comunidades ${ }^{12}$. Por su parte los viudos, con 191 casos, y los varones solteros, con 189 , suponían el 16,4 por ciento del total, es decir, en torno al 8 por ciento de los agregados respectivamente. Tres quintas partes de las mujeres cabezas de familia residian en el mundo rural, aunque su

12 En este sentido, la comarca de Alcaraz se sitúa dentro de unos márgenes ya observados en nuestro pais para otras demarcaciones durante el Antiguo Régimen: entre el 15 y el 20 por ciento para el conjunto de Castilla en los siglos xvi y xvII (MoliniE-Bertrand, A., 1991:269); entre el 12 y el 19 por ciento para Galicia en 1752 (DUBERT García, l., 1992:128); en torno al 13 por ciento tanto en la provincia de Cáceres como en el extenso término jurisdiccional de la ciudad de Lorca a finales del siglo xviII (Hernández Bermejo, M." A.-Testón NúNízZ, I.,1991:147; HurTado MarTinez, J., 1987:304); poco más del 17 por ciento en algunos núcleos rurales mallorquines de principios del siglo XIX (MOLL BLANES, I., 1987:247) o el 20 por ciento de la ciudad de Granada también desde el Catastro del Marqués de Ja Ensenada (CASEY, J.-Víncent, B., 1987:184). Por contra, el rechazo social del celibato y las elevadas tasas de nupcialidad de la zona contlevaban que sólo un 8 por ciento de los hogares encabezados por mujeres fueran solteras.

Hispania, LVIV/I, nún. 195 (1997) 115-145 
presencia dentro del conjunto de agregados no difería excesivamente del porcentaje observado para la ciudad 13 .

\section{CUADRO I}

CARACTERISTICAS DEL HOGAR ENCABEZADO POR UNA MUJER EN LA SIERRA DE ALCARAZ A MEDLADOS DEL SIGLO XVII

\begin{tabular}{|c|c|c|c|c|c|}
\hline ZONA & Núm. & $\%$ & ESTADO CIVIL & Núm. & $\%$ \\
\hline Ciudad & 148 & 40.5 & Soltera & 29 & 8 \\
\hline Aldeas & 117 & 31.9 & Casada & 3 & 0.8 \\
\hline Villas & 101 & 27.6 & Viuda & 333 & 91.2 \\
\hline Total & 366 & 100 & Total & 365 & 100 \\
\hline TIPO HOGAR & Núm. & $\%$ & GRUPO EDAD & Núm. & $\%$ \\
\hline Solitario & 102 & 27.9 & $<25$ & 15 & 4.1 \\
\hline Sin,Estr. & 14 & 3.8 & $25-35$ & 57 & 15.6 \\
\hline Nuclear & 229 & 62.5 & $35-45$ & 74 & 20.2 \\
\hline Complejo & 21 & 5.7 & $45-55$ & 87 & 23.9 \\
\hline Total & 366 & 100 & $55-65$ & 99 & 27.2 \\
\hline \multicolumn{2}{|c|}{ COMPOSICION DEL HOGAR } & & $>65$ & 33 & 9.0 \\
\hline & Total & Media & TOTAL & 365 & 100 \\
\hline & 1143 & 3.12 & & & \\
\hline & 631 & 1.72 & & & \\
\hline & 52 & 0.14 & & & \\
\hline & 94 & 0.25 & & & \\
\hline
\end{tabular}

Fuente: Archivo Histórico Provincial de Albacete (en adelante AHPA), Secc. Catastro del Marqués de la Ensenada, Libros de lo Personal (1753).

Por lo que respecta a la estructura de sus unidades familiares, los datos ofrecidos por el catastro confirman la fuerte proporción de mujeres residiendo en hogares solitarios (casi el 28 por ciento del total) cuando, en conjunto, en toda la comarca dicha proporción, con ser importante, suponía el 12,7 por ciento. Una realidad, por otro lado, que era especialmente más significativa en los pequeños núcleos serranos del Señorío de las Cinco Villas donde suponían nada menos que la tercera parte de sus agregados mientras que tanto en la ciudad como en sus aldeas estaban en torno al 25 por ciento. Por su. parte, las viudas corresidiendo con sus hijos representaban el 62,5 por

13 En 1753 suponían el 14,3 por ciento en la ciudad y el 16,1 en el campo. Sin embargo, los resultados pueden estar distorsionados al estar anexados a la ciudad los datos relativos a sus múltiples heredamientos y caserías. Tanto es aś que según el Padrón calle-hita para la confección del Censo de Floridablanca de! año 1787 (Archivo Local de Alcaraz, Leg. 380), donde ya venía bien delimitado lo urbano y lo rural, las proporciones se invierten: 17,7 por ciento en la ciudad por 14,2 en el campo.

Hispania, LVII/1, nủm. 195 (1997) $\$ 15-145$ 
ciento del total y sólo en el 5,7 por ciento de los casos convivía con ellos algún otro pariente mientras que los agregados sin una estructura definida suponían el 3,8 por ciento.

Por otro lado, como puede comprobarse en el Cuadro I, la probabilidad para las mujeres de encabezar un hogar crecía con la edad: independencia y responsabilidad, pues, venían con los años y con la viudedad. Así, a partir de los 45 años, momento en que las posibilidades de contraer matrimonio o de volverse a casar en el caso de las viudas se habían reducido considerablemente, los porcentajes de mujeres aumentaban de forma vertiginosa, alcanzando más del 60 por ciento del total mientras que con menos de 35 años eran tres veces menos (19,7 por ciento). Pero es más, al contrario de lo que podría pensarse, en nuestra zona la abuela no es, como diría Fauve-Chamoux, una "realidad estadística» ${ }^{14}$. De hecho, incluso después de los 55 años, momento en el que los hijos ya se habian casado, las mujeres viudas no se instalarían en la casa de éstos. Su importancia entre el número de parientes es muy reducida: sólo se han contabilizado desde el Catastro 21 casos para toda la jurisdicción de Alcaraz, es decir, la ciudad más sus doce aldeas dependientes, lo que significaba el 8 por ciento del total ${ }^{15}$. Por otro lado, es en el tramo entre los 55 y los 65 años cuando el número absoluto de mujeres como jefes del hogar es más abultado, descendiendo drásticamente a un tercio desde entonces ( 99 por 33 casos), aunque en nuestra opinión debido al incremento vertiginoso de la mortalidad a partir de estas edades. Pero es que tampoco en el otro extremo, en el caso de las viudas más jóvenes, se refugiarían en la casa de sus padres: en 1753 para toda la ciudad de Alcaraz sólo hemos encontrado 3 casos.

Por todo ello, más que una situación pasajera o transitoria, podemos afirmar que las mujeres, solas o con sus hijos célibes, seguirían encabezando sus propios hogares.

No es extraño, pues, que el tamaño medio de sus agregados fuera muy reducido, situándose claramente por debajo del tamaño comarcal, con 3,12 personas por hogar frente a 4,06 de aquél (si se contabilizan los criados) y de 2,86 frente a 3,67 sin ellos. Con todo, a pesar de la ruptura de la pareja, seguían siendo los hijos el factor más importante para determinar su dimensión ya que suponían el 1,72 de sus miembros mientras que parientes y criados hacían el 0,14 y el 0,25 respectivamente. Parientes entre los que predominaban las mujeres como una clara manifestación del sentido asistencial de dicha corresidencia (así por ejemplo, sólo en la ciudad de Alcaraz y sus aldeas, de un total de 42 parientes, 14 eran varones por 28 mujeres).

\footnotetext{
14 (1981:213).

15 Porcentaje obtenido sobre 264 casos ya que no se han tenido en cuenta 61 casos de parientes cuyos lazos la fuente no especifica. De todas formas, menos frecuente sería aún la corresidencia de los padres de los cabezas de familia, con sólo 4 casos, o la de los abuelos, con l caso. Realidad confirmada también en 1787 por el Padrón calle-hita para la confección del Censo de Floridablanca en la jurisdicción alcaraceña (Archivo Municipal de Alcaraz, Leg. 380), donde se registraban 18 madres, 10 padres y ningún abuelo.
} 
En cualquier caso, $i$ la soledad de viudas y solteras suponía vivir completamente aisladas?. Evidentemente, del mero análisis demográfico poco podemos deducir sobre la realidad cotidiana de estas mujeres. Por contra, como veremos más adelante, hay que recurrir a una información mucho más cualitativa para obtener una visión más cercana y ponderada del grupo.

\section{UNA RADIOGRAFIA DE LA PRECARIEDAD. LA ECONOMIA FAMILIAR DESDE LA ESTRUCTURA DE LA PROPIEDAD}

Pero desde el punto de vista de la propiedad, $\dot{\imath}$ qué hay detrás del grupo mujeres cabeza de familia ?. Como ya dijimos al principio, gracias al cruce de los Libros de lo Personal y los Libros de lo Real del Catastro de la Ensenada es posible obtener una imagen mucho más precisa de su situación. Como puede comprobarse en el Cuadro II, sus hogares acaparaban el 13 por ciento de la tierra en propiedad de los agregados domésticos contabilizados en toda la comarca, a una media de poco más de 7 hectáreas distribuidas en 2,68 parcelas y un producto estimado de 286,11 reales, lo que suponia un promedio por agregado semejante al observado a nivel general $(293,18$ reales), aunque con una productividad mayor que la del resto de sus convecinos $(39,52 \mathrm{rls} / \mathrm{ha}$ frente a 33,61) como consecuencia de una superior presencia entre sus bienes de las tierras de regadío y viña. No en vano, si para toda la comarca el regadío suponía el 6,2 por ciento de la extensión y el 37,3 por ciento del producto estimado de las tierras cultivadas, para las mujeres era casi el 8,3 por ciento de la superficie y nada menos que el 53,6 por ciento del producto. De la misma forma, las mujeres cabezas de familia acaparaban en torno al 14 por ciento de las vides. De otra parte, sólo un reducido número de ellas escasamente complementaban sus ingresos con un 0,52 por ciento de las tierras dadas en arrendamiento por el clero o el 1,26 por ciento de las registradas en administración ${ }^{16}$.

Por lo que respecta al ganado, en sus manos concentraban el 13,7 por ciento de las cabezas contabilizadas, con un promedio global de poco más de 23 por hogar (y ello gracias al ganando menor), lo que prácticamente significaba la misma proporción que para el resto de sus convecinos, si bien para el ganado mayor y de labor tendrían la mitad que aquéllos.

I6 En concreto, desde el Catastro sólo se han contabilizado 11 mujeres como arrendatarias de tierras del clero (con 23,63 has en 13 parcelas y un producto de 1094 reales) y 5 como administradoras de otras procedentes también de capellanías, cofradias, etc, o de otros propietarios seglares foráneos (en total 49,26 has en 35 parcelas y 804,42 reales de producto). Baja participación de la mujer en los arrendarnientos y otras formas de explotación indirecta de la tierra que coincide con la imagen obtenida por Ottega López, M., (1986) para un caso aragonés en la misma centuria.

Hisparia, LVIl/l, núm. 195 (1997) 115-145 
CUADRO II

PRopiedades de las muJeres cabeza de familia en la comarca de alcaRAZ A MEDIADOS DEL SIGLO XVII

\begin{tabular}{|c|c|c|c|c|c|c|}
\hline $\begin{array}{l}\text { TIPO DE } \\
\text { BIEN }\end{array}$ & & MUJERES & COMARCA & $\begin{array}{c}\text { MEDIA } \\
\text { COMARCAL }\end{array}$ & $\begin{array}{l}\text { MEDIA } \\
\text { MUJER }\end{array}$ & $\begin{array}{c}\% \\
\text { MUJER }\end{array}$ \\
\hline \multirow[t]{2}{*}{ CASAS } & Núm. & 239 & 1314 & 0.57 & 0.65 & 18.2 \\
\hline & REALES & 14107.1 & 83265.3 & 36.0 & 38.54 & 16.9 \\
\hline \multirow[t]{3}{*}{ TIERRA } & HAS & 2649.36 & 20173.18 & 8.72 & 7.24 & 13.1 \\
\hline & REALES & 104714.83 & 678128.97 & 293.18 & 286.11 & 15.4 \\
\hline & PARC & 981 & 7131 & 3.08 & 2.68 & 13.8 \\
\hline \multirow[t]{5}{*}{ GANADO } & TOTAL & 8446 & 61550 & 26.61 & 23.08 & 13.7 \\
\hline & $\overline{\mathrm{LABOR}}$ & 153 & 1712 & 0.74 & 0.42 & 8.9 \\
\hline & RENTA & 8293 & 58325 & 25.22 & 22.66 & 14.2 \\
\hline & MAYOR & 643 & 6760 & 2.92 & 1.76 & 9.5 \\
\hline & MENOR & 7519 & 51565 & 22.29 & 20.54 & 14.6 \\
\hline ARRENDA & Núm. ARR & 11 & 251 & 0.11 & 0.03 & 4.38 \\
\hline -MIENTO & HAS & 23.63 & 4550.49 & 1.97 & $0 . \overline{07}$ & 0.52 \\
\hline TIERRAS & REALES & 1094.13 & 139473.78 & 60.30 & 3.07 & 0.78 \\
\hline CLERO & PARCEL & 13 & 926 & 0.40 & 0.04 & 1.40 \\
\hline \multirow{4}{*}{$\begin{array}{l}\text { ADMINI } \\
\text {-TRADORA } \\
\text { TIERRAS }\end{array}$} & Núm. ADM & 5 & 103 & 0.04 & 0.01 & 4.85 \\
\hline & HAS & 49.26 & 3913.69 & 1.69 & 0.14 & 1.26 \\
\hline & REALES & 804.42 & 131406.53 & 56.81 & 2.26 & 0.61 \\
\hline & PARCEL & 35 & 1169 & 0.51 & 0.10 & 2.99 \\
\hline \multirow[t]{4}{*}{ CENSOS } & CONTRA & 153 & 951 & 0.41 & 0.42 & 16.1 \\
\hline & PRINCIP & 88242.68 & 590959.8 & 255.49 & 241.10 & 14.9 \\
\hline & FAVOR & 0 & 88 & 0.04 & 0.00 & 0.00 \\
\hline & PRINCIP & 0 & 215700.82 & 93.26 & 0.00 & 0.00 \\
\hline \multirow[t]{2}{*}{ ARTEFACTOS } & Núm. & 4 & 17 & 0.01 & 0.01 & 23.5 \\
\hline & REALES & 986 & 4163 & 1.80 & 2.69 & 23.7 \\
\hline MEMORIAS & Núm. & 46 & 261 & 0.11 & 0.13 & 17.6 \\
\hline MISAS & Núm. & 76 & 1128 & 0.49 & 0.21 & 6.7 \\
\hline HOGARES & Núm. & 366 & 2313 & & & 15.8 \\
\hline
\end{tabular}

Nota: Se han incluido en los totales también las propiedades registradas en otros térnininos de la comarca diferentes al de residencia. Por otro lado, cuando nos referimos a «comarca" se trata sólo de los bienes contabilizados al conjunto de los cabezas de familia residentes en la misma. "Artefactos" se refiere a la propiedad de molinos, batanes, etc mientras que las casas contabilizadas sólo son las de «moradas (las mujeres disponian de otras 40 casas de campo). «\% \% indica el porcentaje de bienes en propiedad de las mujeres cabezas de casa con respecto al conjunto comarcal.

Fuente: AHPA, Secc. Catastro de la Ensenada, Libros de lo Personal y Libros de lo Real (1753).

Desde la perspectiva de la propiedad agropecuaria, pues, los promedios obtenidos no son en general muy inferiores a los observados para el conjunto 
comarcal. Sin embargo, por el contrario, los niveles de endeudamiento eran ligeramente superiores: el 28 por ciento de las mujeres tenía algún censo en su contra por el 26,2 general, estando sus propiedades cargadas con el 16 por ciento de las escrituras registradas en el Catastro, aunque con un principal por hogar algo inferior al promedio global (241 reales frente a 255). Normalmente se tomarían en préstamo capitales que giraban en torno a los 577 reales por escritura mientras que para el conjunto comarcal sobrepasaban los 620 . Se trata de unas cargas a las que habría que añadir además las procedentes de la titularidad del 17 por ciento de las memorias, aunque dentro del total, el número de misas sólo se redujera al 7 por ciento aproximadamente, una muestra más de su escaso poder de ostentación. Obtenemos así una pobre imagen de sus economías a la que en absoluto contribuirían a modificar tampoco las rentas derivadas de algún censo o juro a su favor.

Era, por contra, la propiedad inmobiliaria la que más destacaba entre sus bienes. Así, mientras que a nivel comarcal la proporción de propietarios de alguna casa era del 46,9 por ciento, entre las mujeres ascendía al 55 por ciento, concentrando en sus manos más de una sexta parte de las mismas (con un valor catastral estimado de más o menos 5 ducados por casa), lo que viene a confirmar cómo efectivamente a las viudas se les dejaba en usufructo la casa o una parte de ella hasta su muerte, corroborando así el catastro la impresión obtenida desde los testamentos ${ }^{17}$. Además poseían 4 de los 17 "artefactos" (molinos o partes de molino fundamentalmente) registrados en el Catastro entre los distintos cabezas de familia.

En definitiva, con una extensión media de 7 hectáreas, un reducido número de cabezas de ganado de renta (en torno a 22) y una mínima capacidad de labranza $(0,42$ bestias de labor por agregado), sus hogares se configuraban como auténticas pequeñas explotaciones que, además, no era raro encontrar cargadas con algún censo y que sólo muy excepcionalmente verían complementados sus ingresos con el arrendamiento o la administración de otras tierras. En cualquier caso, de la comparación de sus resultados con las medias globales obtenidas para el conjunto de la comarca no se deducen grandes diferencias: como le ocurría a la mayor parte de sus convecinos, la pobreza que caracterizaba a un espacio de montaña como éste dejaba un escaso margen para el optimismo a la hora de valorar su situación económica.

Sin embargo, si esta es la imagen general, profundizando algo más en nuestro análisis comprobamos cómo detrás de las cifras globales se escondía todavía una realidad más dura. De hecho, al margen del ejercicio de algún oficio (que desgraciadamente para esta zona, como ya indicamos, la fuente sólo nos proporciona en algunos casos) si adoptáramos como criterios para evaluar el nivel de "bienestar» del hogar la posesión o no de bienes como la tierra y el ganado de renta, y la disposición o no de medios de producción come el ganado de labor o de una fuerza de trabajo dependiente como los criados, tenemos que (véase Cuadro III y Cuadro VII):

1. Efectivamente, como ocurre para toda la comarca, los hogares que contaban con alguna parcela de tierra eran la mitad de los casos, pero de ellos casi el

17 García González, F., (1995:732-733). 
36 por ciento tenían menos de una hectárea frente al 30 por ciento en toda la comarca. Constatamos así una importante polarización en la distribución de la propiedad de la tierra. Sin embargo, gracias a los cultivos de regadío, desde el punto de vista del producto su distribución era semejante: tanto entre las mujeres como para toda la comarca casi el 60 por ciento de las unidades familiares estaban por debajo de los 250 reales, por lo que sólo con la tierra en propiedad muy pocos podrian alcanzar los niveles mínimos de autosuficiencia económica ${ }^{18}$.

2. Si para la tierra las diferencias no son importantes, para el resto de las variables la situación de las mujeres iba paulatinamente degradándose. Así, mientras que sólo en torno a un tercio de las mismas disponían de ganado de renta, tanto de ganado mayor como de ganado menor, para el conjunto de los agregados de la comarca suponía el 48,9 y al 43,5 por ciento respectivamente. Pero es que, además, entre aquéllas que disponían por ejemplo de ganado menor, más del 60 por ciento sólo tenía entre una y cinco cabezas frente al 50 por ciento de toda la comarca.

3. Las diferencias se acentuaban también en aquéllas variables relacionadas con el control de los medios de producción y la fuerza de trabajo como eran el ganado de labor (únicamente el 12,6 por ciento de los hogares disponía de alguna cabeza por el 22,2 comarcal) 19 o los criados, presentes sólo en la décima parte de sus agregados frente al 16,3 por ciento en toda la comarca.

CUADRO III

HOGARES ENCABEZADOS POR MUJERES QUE DISPONIAN DE TIERRAS, GANADO Y CRIADOS A MEDIADOS DEL SIGLO XVII EN LA COMARCA DE ALCARAZ

\begin{tabular}{lcccc} 
TIPO DE BIEN & \multicolumn{2}{c}{ NUMERO DE CASOS QUE NO DISPONIAN DE: } \\
\hline & MUJERES & $\%$ & COMARCA & $\%$ \\
\hline TIERRA & 180 & 49,2 & 1178 & 50.9 \\
\hline G. LABOR & 320 & 87,4 & 1799 & 77.8 \\
\hline G. MAYOR & 249 & 68 & 1182 & 51.1 \\
\hline G. MENOR & 249 & 68 & 1307 & 56.5 \\
\hline CRIADOS & 329 & 89.9 & 1937 & 83.7 \\
\hline & & NUMERO DE CASOS QUE DISPONIAN DE: & \\
\hline TIERRA & 186 & 50.8 & 1135 & 49.1 \\
\hline G. LABOR & 46 & 12,6 & 514 & 22.2 \\
\hline G. MAYOR & 117 & 32 & 1131 & 48.9 \\
\hline G. MENOR & 117 & 32 & 1006 & 43.5 \\
\hline CRIADOS & 37 & 10.1 & 376 & 16.3 \\
\hline
\end{tabular}

Nota: Tanto para la tierra como para el ganado sólo se trata de los bienes detentados en propiedad.

Fuente: AHPA, Secc. Catastro de la Ensenada, Libros de lo Personal y Libros de lo Real (1753).

18 No olvidemos que, desde la misma fuente, el profesor Donézar (1984:148) estima que el producto juzgado como mínimo para la subsistencia sería de 1000 reales en dos años.

19 Situación ligeramente más negativa que la observada por F. Brumont (1984:223) en la Bureba durante el siglo xvı, donde para un número similar de mujeres (360), aún manteniéndose las mismas diferencias con respecto a la media global, el porcentaje de éstas que poseian una yunta era del 16 por ciento frente al 35 por ciento de la población total. Sin embargo, sólo la tercera parte de las mismas contaban con alguna propiedad de tierra. 
Por lo tanto, detrás de los promedios se escondía para las mujeres una realidad más dura que para muchos de sus convecinos. Pero una realidad tam. bién desigual. No en vano, en función de la combinación de las variables anteriores se podría establecer una jerarquía de haciendas (Cuadro IV) que evidencia cómo las mujeres cabezas de familia en absoluto constituían un grupo homogéneo desde el punto de vista de la propiedad ${ }^{20}$. Veámoslo.

\begin{tabular}{|c|c|c|c|c|c|c|c|c|}
\hline \multicolumn{9}{|c|}{$\begin{array}{c}\text { CUADRO IV } \\
\text { MUJERES CABEZAS DE FAMILIA Y TIPO DE HACIENDA EN LA COMARCA DE LA } \\
\text { SIERRA DE ALCARAZ (1753) }\end{array}$} \\
\hline \multirow[t]{2}{*}{ TIPO } & \multicolumn{2}{|c|}{$\begin{array}{l}\text { TOTAL } \\
\text { HOGARES } \\
\text { COMARCA }\end{array}$} & \multicolumn{2}{|c|}{$\begin{array}{l}\text { MUJER } \\
\text { CABEZA } \\
\text { FAMILIA } \\
\end{array}$} & \multicolumn{2}{|c|}{ VIUDAS } & \multicolumn{2}{|c|}{ SOLTERAS } \\
\hline & Nŭm. & $\%$ & Núm. & $\%$ & Núm. & $\%$ & Núm. & $\%$ \\
\hline GRAN & 93 & $\overline{4}$ & 8 & 2.2 & 7 & 2.1 & 1 & 3.4 \\
\hline MED & 596 & 25.8 & 66 & 18 & 64 & 19.2 & 2 & 6.9 \\
\hline PEQ & 1039 & 44.9 & 166 & 45.4 & 148 & 44.5 & 16 & 55.2 \\
\hline SIN & 585 & 25.3 & 126 & 34.4 & 114 & 34.2 & 10 & 34.5 \\
\hline TOTAL & 2313 & 100 & 366 & 100 & 333 & 100 & 29 & 100 \\
\hline
\end{tabular}

Nota: $\mathrm{Gra}=$ Gran propiedad; Med= Mediana propiedad; $P e q=$ Pequeña propiedad; $\operatorname{Sin}={ }^{\mathrm{S}} \mathrm{Sin}$ labranzas ni crianzas*. De las 3 mujeres casadas con el marido ausente, 1 es una pequeña propietaria y 2 no tienen ni «labranzas ni crianzas». Hay una mujer de la que desconocemos su estado civil y que estaría entre la pequeña propiedad.

Fuente: AHPA, Secc. Catastro de la Ensenada, Libros de lo Personal y Libros de lo Real (1753)

\section{MUJERES CABEZAS DE FAMILIA: DESIGUALDAD Y ADAPTACION}

En esta zona del interior castellano, la mujer en absoluto quedaba relegada a un segundo plano en el proceso de transmisión de la propiedad ${ }^{21}$. Todo lo contrario: era pieza clave en dicho proceso al poder transmitir bienes de forma directa a través de la dote y ser receptora a partes iguales de las propiedades del padre y de la madre. Pero además, las viudas, después de la muerte del marido, podían recuperar su dote, la mitad de los bienes gananciales e incluso beneficiarse de las disposiciones de aquél en su favor, quedando en la mayoría de las ocasiones como tutora de sus hijos y administradora de sus bienes (algo que podfa tener efectos acumulativos si se casaba dos o más veces). Por ello, a priori, es posible que su situación no fuera tan dramática como podría pensarse si era normal que la viuda sacase la parte

20 Sobre los criterios seguidos para dicha jerarquización vid. GARCLA GONZALEZ, F., (1995: 618-630).

21 Para un planteamiento más general véase por ejemplo CHACón JiMÉNEZ, F., (1990) y en concreto su trabajo Continuidad de costumbres y transmisión de la propiedad en el sistema familiar castellano, siglos XVI-XVIII; E. Gacto (1987) o M. Garcia Fernández (1995).

Hispunia, LVIl/1, núm. 195 (1997) 115-145 
del león de la herencia ${ }^{22}$ a tenor de ejemplos como el de Teresa García Valladolid, viuda del ganadero Bartolomé Romero de Coca, que se aprovecharía de un impresionante patrimonio estimado en 117.269 reales como beneficiaria y tutora de sus 5 hijos: a la parte correspondiente de sus ganaciales (35.033 reales) añadio 3.300 reales de su dote, responsabilizándose además de otros 38.383 reales para hacer efectivo el pago de diferentes deudas ${ }^{23}$.

Sin embargo, como es lógico, la muerte de los padres o la pérdida del cónyuge no daba lugar a las mismas situaciones. Si bien desde la perspectiva material para la mujer la dote no sólo resultaba indispensable para contribuir a la formación de un nuevo hogar sino también para garantizar su vejez o viudedad, una mirada más atenta desde el análisis de los testamentos nos indica que, en un contexto donde predominaban los pequeños propietarios y los hogares que podríamos denominar como López Salazar ${ }^{24}$ sin labranzas $n i$ crianzas (véase cuadro IV) no todas las hijas llevaron bienes al matrimonio y cuando lo hicieron difícilmente pudieron servirles como seguro material ya que se trataba simplemente de un homenaje y trastillos de casa pobre, por lo general situado en torno a los 100 reales y siempre valorado por debajo de los 500 . En concreto, ante la poca frecuencia de registrar notarialmente las dotes en esta zona, si nos atenemos a la información contenida en los testamentos relativa a los bienes que cada uno de los cónyuges aportó al matrimonio, obtenemos que sólo el 45 por ciento de las mujeres llevó algún tipo de bien en el momento de iniciar su andadura el nuevo hogar. En promedio el valor de lo aportado ascendería a unos 2687 reales, aunque en realidad casi la mitad de los casos estaban por debajo de los 500 reales y en conjunto el 65 por ciento no superaban los $1000^{25}$. Y ello sin olvidar que, por lo general, sólo nos estamos refiriendo a las mujeres que disponian de alguna propiedad para testar e ir al notario. Pero además, por otro lado, son pocos los testamentos que aluden a los bienes gananciales (signo evidente de las dificultades de la pareja para incrementar el patrimonio inicial), o a la transmisión de legados, donaciones y mejoras ( $\mathrm{y}$ en este caso, aunque se tendía a beneficiar a la mujer, cuando se hacía era más bien como un medio de compensación que como una práctica con una clara finalidad estratégica) ${ }^{26}$.

22 CASEY, J.-VINCENT, B., (1987:198).

23 AHPA, Secc. Protocolos Notariales, Leg. 320, Exp. 3, fol. 153 y ss, Inventario de partición de bienes de Bartolomé Romero de Coca $(23 / 6 / 1769)$. Su caso guarda un enorme parecido con el de Antonia de la Chica, estudiada por los citados James Casey y Bernard Vincent (1987:194-198), aunque esta vez se trataba de la viuda de un curtidor de la ribera del Darro en Granada.

24 (1986:506).

25 Cálculos establecidos sobre un total de 292 testamentos de mujeres: 174 casadas y 118 viudas. Por el contrario, entre los mismos protocolos notariales consultados sólo se han podido localizar 38 escrituras de dote (sin contar las religiosas).

26 De un total de 697 testamentos consuitados para toda la cornarca a lo largo del siglo xviII, en menos de la mitad de las escrituras $(48,5$ por ciento) se hacía alusión a este tipo de transmisión de la propiedad, considerándose sólo como tales «mejoras» al 11,6 por ciento de las mismas (81 casos). Efectivamente la mujer saldría más favorecida al ser beneficiada con el 55 por ciento de dichos legados por el 45 por ciento de los hombres. Con todo, en la mayoría de las ocasiones se trataba de ropas de vestir y de cama, trastos de casa, etc. 
Como consecuencia, no es extraño que los hogares sin labranzas ni crianzas supusieran casi el 35 por ciento de los agregados de las mujeres cabezas de familia y más de la quinta parte de los contabilizados en todo el conjunto de la comarca y que, en todo caso, aparte de su ajuar, como hemos visto desde el Catastro, muchas de ellas sólo tuvieran una parcela de tierra cuasiimproductiva o algún cerdo para el consumo familiar: si en total más del 46 por ciento de sus hogares se incluían dentro de la pequeña propiedad, tres cuartas partes se situaban en su límite inferior. Por contra sólo un reducido 18 por ciento se constituían como medianas propietarias y un testimonial 2 por ciento (8 casos) como grandes propietarias ${ }^{27}$. Coincidimos así con Brumont cuando, con respecto a las viudas, afirma que «la viuda rica no es un mito de nuestros campos, pero es muy rara" 28 .

En definitiva, no encontramos muchos casos con una propiedad aceptable entre el grupo de mujeres cabezas de familia, constatándose así la imagen de precariedad e inseguridad económica que caracterizaba a las viudas, y en general a la mujer, en el Antiguo Régimen. Por el contrario, según nuestros datos, casi cuatro de cada cinco unidades familiares dirigidas por mujeres serían tremendamente susceptibles a los efectos de coyunturas negativas. De ahí que, como ha estudiado Stuart Woolf ${ }^{29}$, fuera este grupo quien más fácilmente traspasaría el límite de la supervivencia para caer en la pobreza más absoluta. La búsqueda de estrategias para evitarlo sería, como veremos, su principal objetivo de la misma forma que seguir reproduciendo y perpetuando la desigualdad era algo intrínseco a cualquier sistema social jerarquizado. En este sentido, en el Antiguo Régimen la dote se había convertido en uno de los principales mecanismos para ello. La reciprocidad en los intercambios inherente al establecimiento de las alianzas no sólo dió lugar a una relativa homogeneidad en la condición social de los nuevos esposos, sino que, como los bienes dotales siempre regresaban a su origen familiar cuando se producía la separación de la pareja, a través de matrimonios consanguíneos se conseguiría la perpetuación y reproducción de sus patrimonios dentro de las redes del parentesco. De ahí que al mismo tiempo que se invertía en parentesco se invertía en perpetuación y que fuera uno de los medios más utilizados por los grupos de poder para preservar el status adquirido dentro de la comunidad ${ }^{30}$. Un ejemplo: don José Henares, Gobernador del Señorro de las

27 En promedio las haciendas de las grandes propietarias se componian de 136,5 has con un producto estimado de 4902 reales; 685 cabezas de ganado menor y 19,2 de ganado mayor; 4,37 cabezas de ganado de labor y 6 criados. Las medianas propietarias disponian de 17,34 has y un producto estimado de 690,5 reales; 26 cabezas de ganado menor y 5,7 de ganado mayor; 1,78 cabezas de ganado de labor y 0,63 criados. Y por último, las pequeñas propietarias tenían 2,46 has con un producto estimado de 114,3 reales; 1,9 cabezas de ganado menor y 0,65 cabezas de ganado mayor. Evidentemente las incluidas dentro del grupo «sin labranzas ni crianzas» no disponian de ninguno de estos bienes.

28 (1984:223). Realidad constatada también por Molinié-Bertrand, A., (1991:273-274).

29) (1989:175-217).

3) A este respecto véase Rodriguez SÁnChEZ, A., (1992) O CHACón JiMÉnez, F., (1995).

Hispania. LVIJ/1, แt่m. 195 (1997) 115.145 
Cinco Villas de la Sierra de Alcaraz y miembro de una de las familias de labradores y ganaderos más ricas de la villa de Bienservida, los Henares Valero (cuya presencia de forma continuada en instituciones como el concejo o la Gobernación del Señorío hemos constatado desde mediados del siglo XVIII hasta los años 30 de la centuria siguiente), casó a su hija Francisca con su sobrino carnal Pedro Henares dotándola con más de 32.000 reales ${ }^{31}$. Una impresionante cantidad que en esta zona estaba al alcance de muy pocos: entre los testamentos y cartas de dote consultadas sólo se han encontrado dos y cuatro casos respectivamente que rebasaron los 25.000 reales. Ello muestra la tremenda diferenciación social existente en esta comarca ya que entre los testamentos estos dos casos suponían el 35 por ciento del montante total de los bienes aportados y entre las dotes casi la mitad.

Se trata además de una diferenciación que tenfa también su correlato a nivel espacial. A pesar del escaso número de dotes encontrado ( 38 escrituras), es significativo que en la ciudad de Alcaraz se concentraran tres cuartas partes de la cuantía total de los importes contabilizados y que su valor por escritura doblara al del mundo rural (12.647 reales por 6.160). En este sentido, la presencia en la ciudad de miembros pertenecientes a los oficios burocráticoadministrativos y, sobre todo, de la hidalguía local explica estas desigualdades. Un magnífico ejemplo de ello es el caso de doña Bernarda Valenzuela, viuda del gran terrateniente, regidor e hijosdalgo don Alfonso Isidro Blázquez Fernández de Córdoba, el propietario laico residente en la comarca a mediados del siglo xviII más rico según el Catastro de la Ensenada. Natural de El Horcajo (Cuenca), llevó como dote a su matrimonio 49.500 reales mientras que su marido aportó más de 110.000 reales (agregando posteriormente otros 22.000 con la compra de un hato de machos cabríos y otros 28.000 al comprarle a sus tres tías religiosas sus bienes) ${ }^{32}$. Con 34 años ya habría enviudado, haciéndose cargo como tutora de sus dos hijas menores del ingente patrimonio familiar y además de la parte de herencia que le correspondía a su marido como sobrino por vía materna de doña Elvira Auñón, otra de las pocas mujeres poseedoras de un patrimonio importante según el Catastro de la Ensenada (aunque, soltera y de avanzada edad, no venía registrada como cabeza de familia al vivir en las casas de su sobrino) ${ }^{33}$.

31 AHPA, Secc. Protocolos Notariales, Leg. 403, fol. 3-6v, Carta de dote de Francisca Henares (10-1-1783).

${ }_{32}$ AHPA, Secc. Protocolos Notariales, Leg. 313, Exp. 5, fol. 27v-28. Testamento de don Alfonso Isidro Blázquez Fernández de Córdoba (9-4-1755). En el Catastro de la Ensenada venía como propietario de 868,87 has distribuidas en 74 parcelas y un producto estimado en 17.139 reales, 2264 cabezas de ganado menor, 5 de ganado de labor y 15 de ganado mayor.

33 Según el Catastro disponia en 1753 de 481,72 has distribuidas en 68 parcelas (algunas de ellas plantadas de vides, en total 5.700) con un producto estimado de 15.817 reales además de 2 casas de morada y 4 de campo. Sobre su partición véase AGS, DGR, 1. ${ }^{a}$ Remesa, Leg. 1484, Fol. 1,, «Comprobaciones de la ciudad de Alcaraz y sus terratenientes» (año 1761). Relaciones 296, 297, 298,299 y 300 . Catorce años después de las primeras operaciones catastrales sabemos que doña Bernarda Valenzuela, con 40 años, todavia se mantendría viuda y residía con sus dos hijas en la calle de la Compañia de Jesús. ADA, Lib. Alz 124, Libro de Matrícula de la lglesia de San Miguel (año 1767 ), casa número 142 . 
Por lo tanto, dentro de un contexto marcado por la precariedad y la división igualitaria de los bienes (independientemente de que se realizara post mortem o inter vivos) asi como por las estrategias adoptadas por los grupos de poder para seguir perpetuando su status, pocas sorpresas podían esperarse desde el punto de vista de la transmisión de la propiedad en la jerarquización de sus haciendas. Sin embargo, en comparación con las proporciones obtenidas para toda la comarca (Cuadro IV), la presencia de las mujeres como cabezas de familia se iba incrementando a medida que descendiamos en los niveles de la propiedad. Y aquí, aparte de las consecuencias derivadas de las decisiones estratégicas vinculadas al género y de la posible distorsión que ello implicaría dentro de un modelo hereditario teoricamente equitativo ${ }^{34}$, debemos preguntarnos si sus hogares se empobrecían cuando pasaban a estar encabezados por una mujer. Es evidente que para las mismas la desaparición de los padres o del cónyuge no equivalía irremediablemente a la destrucción de la explotación familiar, pero sin duda sí significaría económicamente un duro golpe como refleja el Cuadro V.

\section{CUADRO $v$}

TIPO DE HACIENDA SEGUN ESTADO CIVIL Y SEXO DE LOS CABEZAS DE FAMILIA EN LA COMARCA DE LA SIERRA DE ALCARAZ (1753)

\begin{tabular}{|c|c|c|c|c|c|c|c|}
\hline TIPO & $\begin{array}{l}\text { MUJER } \\
\text { CABEZA } \\
\text { HOGAR }\end{array}$ & $\begin{array}{l}\text { VARON } \\
\text { CABEZA } \\
\text { HOGAR }\end{array}$ & $\begin{array}{c}\text { PAREJA } \\
\text { COMPLETA }\end{array}$ & VIUDA & VIUDO & SOLTERA & SOLTERO \\
\hline GRAN & 2.2 & 3.1 & 4.6 & 2.1 & 3.4 & 3.4 & 2.7 \\
\hline MED & 18 & 22.2 & 27.6 & 19.2 & 25.4 & 6.9 & 18.3 \\
\hline $\mathrm{PEQ}$ & 45.4 & 48.5 & 44.7 & 44.5 & 50.3 & 55.2 & 46.3 \\
\hline SIN & 34.4 & 26.2 & 23.1 & 34.2 & 20.9 & 34.5 & 32.7 \\
\hline TOTAL & 100 & 100 & 100 & 100 & 100 & 100 & 100 \\
\hline
\end{tabular}

Nota: Gra= Gran propiedad; Med= Mediana propiedad; $P$ eq= Pequeña propiedad; $\operatorname{Sin}=* \operatorname{Sin}$ labranzas ni crianzas". Para no desvirtuar las comparaciones, entre los hombres no se han contabilizado a los cabeżas de farnilia pertenecientes al clero. Datos en porcentajes.

Fuente: AHPA, Secc. Catastro de la Ensenada, Libros de lo Personal y Libros de lo Real (1753)

Desde la propiedad dicho cuadro nos muestra una clara graduación de la diferente situación en la que se encontrarían los distintos agregados domésticos según el estado civil y el sexo de los cabezas de familia: mientras que el matrimonio se confirma como la opción más rentable y eficaz en una sociedad donde las unidades familiares constituian la base del sistema socio-económico (compárense por ejemplo los agregados compuestos por una pareja con los encabezados por un varón o una mujer en el caso de la mediana propiedad o los hogares sin labranzas ni crianzas), la desaparición de la pareja era más negativa para las mujeres que para los hombres (entre las viudas los

34 Vid. por ejemplo Martinez LópEZ, D., (1996) sobre el desigual acceso a la propiedad de la tierra y la importancia del género en su determinación.

Hispania, LVI1/1, núm. 195 (1997) 1\$5-145 
hogares sin crianzas ni labranzas suponían más del 34 por ciento frente al 21 por ciento de los viudos o el 19 y el 25 por ciento respectivamente para la mediana propiedad) al igual que entre los solteros los varones (entre los que un 18 por ciento eran medianos propietarios) estaban en una posición mucho mejor que las féminas. Por su parte los viudos tendrían unas explotaciones más equilibradas y dotadas que los solteros, como ocurría también entre viudas y solteras.

En cualquier caso, dentro de la variedad de situaciones existente, la edad de la mujer es una de las principales variables a tener en cuenta. Así, los agregados de las mujeres más jóvenes serían los más afectados por la desgracia. De hecho, aún hoy, para las viudas más jóvenes algún trabajo de campo señala cómo económicamente la muerte del marido suponía llevarse la llave de la despensa ${ }^{35}$. Pero además no debemos olvidar que la dote no constituía por lo general el total de los bienes familiares a percibir por la hija, sino que habría que esperar a la muerte del padre o de la madre para recibir el resto de sus respectivas legítimas. Por todo ello no es extraño que este colectivo estuviera situados en los niveles más bajos de la propiedad: mientras que entre las menores de 45 años sólo un 15 por ciento tenían unas propiedades aceptables entre las mayores de dicha edad había casi un 24 por ciento. Hacienda y edad por lo tanto se correlacionaban, reflejándose también en la mayor o menor dimensión y complejidad estructural de sus agregados: a grosso modo ambas variables aumentaban con el tamaño de la hacienda y la edad, simplificándose al contrario, con una clara tendencia al hogar solitario, si se carecía de la misma (véase el Cuadro VI).

CUADRO VI TAMAÑo, ESTRUCTURA DEL hOGAR Y PROPORCION DE MUJERES CABEZAS DE FAMILIA MAYORES O MENORES DE 45 AÑOS SEGUN TIPO DE HACIENDA (1753)

\begin{tabular}{|c|c|c|c|c|c|c|c|c|c|c|}
\hline TIPO & $\begin{array}{c}\text { HOGA } \\
\text {-RES }\end{array}$ & $\begin{array}{c}\text { TAMA- } \\
\text { No }\end{array}$ & $\begin{array}{l}\text { SOLI- } \\
\text { TARIOS }\end{array}$ & $\%$ & $\begin{array}{c}\text { COM- } \\
\text { PLEJOS }\end{array}$ & $\%$ & $<45$ & $\%$ & $>45$ & $\%$ \\
\hline GRA & 8 & 9 & 3 & 37.5 & 0 & 0 & 3 & 37.5 & 4 & 62.5 \\
\hline MED & 66 & 4.03 & 10 & 15.1 & 6 & 9.1 & 19 & 28.7 & 47 & 71.2 \\
\hline PEQ & 166 & 2.87 & 44 & 26.5 & 10 & 6 & 64 & 38.5 & 100 & 61.4 \\
\hline SIN & 126 & 2,60 & 45 & 35.7 & 5 & 3.9 & 60 & 47.6 & 64 & 52.4 \\
\hline
\end{tabular}

Fuente: AHPA, Secc. Catastro de la Ensenada, Libros de lo Personal y Libros de lo Real (1753)

Sin embargo, a pesar de ello, las expectativas de futuro de las mujeres jóvenes, viudas o no, eran muy diferentes a las de aquéllas que contaban con una edad más avanzada: mientras que las primeras siempre tenía más opciones para casarse o volverse a casar, éstas últimas sabían sus escasas posibili-

35 ALBERDI, I., (1988:104). Situación dificil senalada también para la viudedad en general por TiLLY, L.A.-SCOTT, J. W. (1987:70) o HuftON, O., (1991: 53-57). 
dades ${ }^{36}$ y que, en consecuencia, debían ser ellas mismas, si disponían de propiedades, quienes tendrían que preocuparse por afianzar y preservar la posición y el patrimonio familiar.

En concreto, para las viudas, a partir de la muerte del marido su principal problema sería hacer frente en solitario a sus responsabilidades familiares, asumiendo tanto los roles afectivo-doméstico como económico-sociales. Es decir, en palabras de Astete, refiriéndose precisamente a las viudas que disponían alguna hacienda, han de ser padre y madre para sus hijos y señor para sus criados ${ }^{37}$ cuando los había. No hay duda sobre su capacidad para realizar los diferentes trabajos agrícolas o dirigir sus explotaciones, como ilustra el caso de María Muñoz de la pequeña villa de Villaverde del Guadalimar, que tenía a su cargo 15 criados para hacer frente a las necesidades de su enorme propiedad ${ }^{38}$, pero lo más frecuente era que, en contra de los criterios eclesiásticos, muchas procuraron volverse a casar. Y no era para menos a tenor de las dificultades con las que seguramente se encontrarian. Aprovecharse de la división del trabajo dentro del agregado doméstico no siempre fue posible y el papel del marido en pocas ocasiones pudo ser sustituido por los hijos o por los criados ( $y$ menos por los parientes dada su escasa presencia como corresidentes en sus hogares y su marcado carácter asistencial). Así, por ejemplo, sólo el 7,6 por ciento de sus hijos (48 casos) eran varones y tenían 25 o más años y también sólo en torno al 10 por ciento de los agregados disponian de mozos de labor. Pero además, aparte de los escasos bienes aportados al matrimonio y de las pocas veces que se obtuvieron gananciales, muchas tuvieron que cumplir con las mandas de su marido o ceder a sus hijos la parte correspondiente a sus legitimas paternas, vender algunas de sus propiedades (especialmente cuando se trataba de circunstancias excepcionales, por ejemplo cuando sus maridos estaban ausentes o en prisión) ${ }^{39}$ o hacer frente al pago

36 En general, si a medida que avanzaba el ciclo vital las posibilidades de contraer nupcias disminuian bruscamente, esto ocurría con especial rapidez para las mujeres ya que, dentro de una sociedad donde la reproducción demográfica implicaba mantener elevados niveles de fecundidad, por encima de una cierta edad aquéllas dejaban de tener «valor» en el mercado matrimonial (REHER, D .S., 1994:74-75), Esto implicaba por lo tanto que, al margen de otras consideraciones, al tener ef poder reproductivo, la capacidad de tener hijos, muchas viudas jóvenes seguirian siendo atractivas dentro de dicho mercado mientras que tanto las mujeres solteras que sobrepasaban cierta edad como las viudas mayores, con las que se equiparaban aquéllas, quedaban relegadas a un segundo plano.

37 Citado por Vigil, M., (1986:201). Expresiones semejantes son recogidas por KLAPISCHZUBER, C., (1990:258) para aludir en general a las bonnes mères florentinas, cuyas virtudes, al margen de las tareas domésticas y educativas, tenían, en consonancia con la sociedad donde vivian, unas claras connotaciones masculinas.

38 Con 48 años y 5 hijos, disponia de 4 pares de labor, 1567 cabezas de ganado menor, 69 de ganado mayor y 168,16 hectáreas con un producto estimado de 6987 reales. Muestras de su competencia como gestoras agrícolas las encontramos incluso en la Polonia señorial, donde era más fácil colocar a la mujer sola a la cabeza de toda una explotación con personal asalariado que al hombre solo (IZYDORCZYK- KAMLER, A.- WYCZANSKI, A., 1990:282).

39 Fulgencia Tarrazaga, mujer de Diego Pérez, decía expresamente que tuvo que vender una huerta a don Francisco Cenón Hinojo, Gobernador del Señorio de las Cínco Villas y con quien

Hispania, LVII/I, núm. 195 (1997) 115-145 
de las deudas contraídas (no olvidemos que el nivel de endeudamiento de las mujeres cabezas de casa superaba ligeramente, con el 28 por ciento de los casos, al promedio comarcal). El caso de Agueda Gómez, de 62 años y viuda del labrador Rodrigo Rubio, de Bienservida, es paradigmático en este sentido: de los bienes que su marido declaró en 1753 ocho años después sólo le quedaba la casa y una fanega y nueve celemines de tierra con 600 vides más una cerda con cuatro crías. Los demás bienes se distribuyeron de la siguiente forma: el solar, teinada y pajar así como dos parcelas de tierra con árboles de 8 y 4 celemines fueron vendidos; otras dos parcelas de 5 celemines y 12 fanegas las dejó su marido como manda a dos de sus sobrinos, y la pieza de tierra de 500 vides la dí por el censo con el que estaba cargada ${ }^{40}$. Problemas de los que tampoco se libraron algunas mujeres pertenecientes al grupo de la hidalguía local alaraceña, como ejemplifica doña Vicenta del Corro y Bustamante, quien se quejaba de que su hijuela había perdido valor (de un montante global de 25.789 reales se había reducido a 18.588 reales) debido a los más de 7.000 reales de deudas que había contrádo desde que murió su padre, el regidor e hijosdalgo don Juan Manuel del Corro y Bustamante, hasta que se casó con don Pedro Venancio de Arias, que pasaría a detentar su regiduría ${ }^{41}$.

Nuestros datos en este sentido son extraordinariamente significativos: comparando la situación de 98 hogares en dos momentos distintos (1753 y 1761) en los que dichos hogares seguían estando encabezados por una viuda o habían accedido a su jefatura durante este período tras la muerte de sus respectivos maridos, obtenemos que en el 53,1 por ciento de los casos se habían vendido algunas parcelas o se habían dado en herencia, consumido o perdido algunos o todos los bienes; en un 38,7 por ciento permanecían sin cambios y sólo en un 8,2 por ciento habían ampliado su propiedades, bien mediante compra o herencia ${ }^{42}$. Por ello, en general, cabe deducir (corroborándose así la impresión obtenida desde el Cuadro V) que para las mujeres la viudedad

colindaba, por 2260 reales para alimentar a sus ocho hijos al encontrarse aquél en la cárcel. AHPA, Secc. Protocolos Notariales, Leg. 403, fol. 33v-35v. Venta real de una huerta a favor de don Francisco Cenón Hinojo (15-X-1794).

40) AGS, DGR, 1." Remesa, Leg. 1484. Comprobaciones del Catastro del Marqués de la Ensenada (1761) correspondientes a la villa de Bienservida.

${ }_{41}$ Entre los bienes más valiosos de su hijuela figuraban un hato de 250 cabezas de cabrio por un valor de 11.285 reales; tres mulas (dos de labor) por 1.700 reales; 30 fanegas de barbecho por 600 reales; 30 fanegas de trigo y 26 de cebada por 1.256 reales, y 3 pollinos por 540 reales. Entre sus deudas figuraba, entre otros conceptos, el arrendamiento de la labor de la Potrera y varias cuentas con el Pósito de la ciudad. AHPA, Secc. Protocolos Notariales, Leg. 317, Exp. 1, fol. 66-71. Carta de dote de doña Vicenta del Corro y Bustamante (15/08/1764).

42 Resultados obtenidos del análisis exhaustivo de las Comprobaciones del Catastro del Marqués de la Ensenada (1761) correspondientes a las 12 aldeas de la ciudad de Alcaraz y a las villas de Bienservida, Cotillas, Villapalacios o Villaverde. Aunque sería deseable contar con un mayor soporte empirico, otros indicios apuntan en la misma dirección: del análisis del Legajo 403 referido a la villa de Bienservida y centrado en el periodo 1780-1796 (junto con otros expedientes del año 1764 y otras noticias dispersas), comprobamos que de 25 escrituras de compraventa en las que uno de los dos otorgantes era una mujer viuda o soltera, 17 eran de venta frente a 8 que eran de compra. 
entrañaba más bien un empobrecimiento y debilitamiento económico del hogar como, por otro lado, ya indicaba Alonso de Andrade a mediados del siglo XvII, quien en boca de una viuda decía que

por cuanto que mi hacienda se me pierde cada día: la hacienda que los míos me dejaron se me destruye, los criados se me descomiden; no tengo quien hable por mi, ni quien me defienda en mis pleitos, ni quien crie mis hijos ${ }^{43}$.

Sin embargo, en ocasiones, más que una solución, las segundas nupcias se convirtieron en un verdadero problema como ilustra el ejemplo de la mediana propietaria María Martínez, moradora en el heredamiento de La Hoz. Viuda con una hija de corta edad, contrajo de nuevo nupcias con Juan Rodríguez, que no llevó nada al matrimonio. Por contra, ella, además de aportar una dote valorada en más o menos 3000 reales (compuesta por una labor de tierras, dos vacas y diversos muebles) administraba también las propiedades que su primer marido llevó al mismo y que, entre otras cosas, eran una casa, once vacas y aperos de labrador. Sin embargo, la referida viuda se quejaba amargamente en su testamento de que su actual cónyuge, con el que tuvo otro hijo, no sólo era poco trabajador y había consumido muchos bienes, sino que incluso quería vender la labor que heredó de sus padres y ella

abiéndome escusado varias vezes empezó a usar de rigor conmigo para conseguirlo y biendome estrechada y con muchas pesadumbres...hasta darle permiso para ello contra toda mi voluntad...se hizo papel simple por cuanto he ydo estorbando el azer escritura formal...por ser en mi perjuizio y daño de dha mi hija porque intenta ir consumiendo todo y con poca aplicación al trabajo ${ }^{44}$

Por lo tanto, no sería raro que muchas, cuando era notorio que no podían hacer frente solas a sus propiedades, volvieran a casarse con individuos con una situación económica inferior a la de su primer marido ${ }^{45}$,

${ }^{43}$ Aunque esto para otros, como Astete, sería la excusa para ocultar su flaqueza y lascivia, idea en cierto modo compartida por Juan de Pineda, para quien las viudas, si tenían qué comer, estaban ociosas en sus casas, eran curiosas y «parloncillas» y daban que hablar por su soltura y poco celo de su honor. Vid. VIGlL, M., (1986:199,202 y 205). También KLAPISCH-ZUBER, C., (1990:258-259) desde el caso florentino señala cómo las sospechas sobre estas mujeres eran permanentes. Así, juristas, moralistas y otros pensadores sobre la familia contribuyeron a consolidar una imagen de la viuda como mujer ávida y caprichosa, sin piedad por sus hijos, inconstante en sus obligaciones familiares, insaciable y proclive a una sexualidad desordenada. Son muestras todas ellas de la prolongación a to largo de los siglos XV, xvl y xvul de la tradicional misoginia medieval que, sin embargo, como señala LóPEZ-CORDóN, M. ${ }^{2}$ V., (1994:106), en el siglo xvill sufriría un cambio espectacular al considerarse a las mujeres como inocentes y puras, aunque eso si, débiles.

44 AHPA, Secc. Protocolos Notariales, Leg. 312, Exp. 2, Testamento de María Martínez, fol. 40v-41, (6/4/1763). Es en este sentido como autores como M. CARBONELL (1990:127) consideran que, aun siendo el matrimonio desde el punto de vista económico la opción más eficaz para hombres y mujeres, para estas últimas sería una alternativa menos efectiva y rentable que para los hombres al quedar aquéllas subordinadas a éstos.

45 Algo que también apuntan TiLLY, L.A.-.Scort, J.W., (1987:70).

Hispaniu, LVI1/1, núm. 195 (1997) \$15-145 
En cualquier caso, para la mayoría de las mujeres seguramente su situación y la de su familia se alivió al contraer nuevas nupcias, sobre todo entre aquéllas que sólo contaban con un mínimo patrimonio familiar ${ }^{46}$. Y ello a pesar de que los bienes aportados por el nuevo marido fueran escasos ya que, aunque no dejara de reproducirse la precariedad, al menos garantizarían su subsistencia y la de sus hijos, como ilustra por ejemplo el caso de Sebastiana, viuda que volvió a casarse con el pequeño labrador Lucas de Villalón: mientras que él llevó al matrimonio un buey, un pollino y un poco trigo y cebada (1000 reales en conjunto), ella no aportó nada, excepto a un hijo llamado Manuel García, con quien además el mencionado Lucas gastó 200 reales en enseñarle el oficio de zapatero ${ }^{47}$.

De la misma forma, para las mujeres solteras y huérfanas, disponer de un mínimo patrimonio que aportar al matrimonio sería la solución para su futuro. De ahí el interés por asegurar el porvenir de los descendientes y las distintas formas de previsión generacional encontradas en algunos testamentos. Por ejemplo, el presbítero don Tomás Jiménez Ruiz cedía, como ayudas al matrimonio de su sobrina Rosa García Jiménez con Francisco Javier Romero de Coca, un "peujar" de yeguas con sus crías de mular y caballar, dos burros y diecisiete cerdos siempre y cuando dicho marido otorgara luego como dote a cada una de sus tres cuñadas menores 3.300 reales a medida que se fueran casando ${ }^{48}$. Interés que incluso podía convertirse en algo colectivo al ser un problema asumido por algunas instituciones cuando se trataba de mujeres procedentes de las clases más desfavorecidas, como ocurría con el patronato que en la villa de Villapalacios fundó Ana Serrano, que tenía como carga 200 reales que se daban como prebenda a huérfanas doncellas en el momento de tomar estado ${ }^{49}$. Por el contrario, entre los grupos de poder estos legados servirían para reforzar la posición económica y el status social de la novia, como ilustra el caso de doña Josefa Asenjo y Vargas, hija del regidor de

46 Como señala CARASA Soto, P., (1994:270) desde el caso de Burgos en el siglo xIX: para la mujer sujeta a precariedad el matrimonio representaba una salida a la pobreza.

47 De la misma forma, Beatriz Bermúdez, de Bienservida, que estuvo casada en primeras nupcias con el mozo sirviente Juan Gallego (quien había aportado cortos bienes que se consumieron antes de morir) contrajo de nuevo mattimonio con Alonso de Lorca, que igualmente sólo llevó 18 ovejas y sus ropas de vestir. Ella por su parte llevó la casa y sus correspondientes muebles (todo ello valorado en 530 reales). Sin embargo, este nuevo matrimonio le permitió que en el momento de su herencia, al hijo que tuvo con su primer marido le dejara un añojo y cinco cabras paridas y la hija que tuvo con el segundo el ajuar y un telar. Ambos quedaron como sus herederos universales y su marido como curador de la hija que era todavía menor. AHPA, Secc. Protocolos Notariales, Leg. 285, Testamento de Lucas de Villalón (22/1/1708); Leg. 403, Testamento de Beatriz Bermúdez, fol. $32 \mathrm{v}-34 \mathrm{v},(14 / 7 / 1781)$.

48 AHPA, Secc. Protocolos, Leg. 318, Exp. 1, s.f., (17/3/1769).

49 Esto mismo encontramos también en la villa de Riópar con el patronato que fundó Pedro Martínez Millán, cuyas rentas se distribuirian en casar huérfanas parientes del fundador o pobres vergonzantes de la villa. AHPA, Secc. Catastro del Marqués de la Ensenada, Libro de lo Real del Estado Eclesiástico de Villapalacios, Libro 206, Relación núm. 5; y Libro 165, Relación núm. 13, para Riópar.

Hispania, LVIVI, núm. 195 (1997) 115-145 
la ciudad de Alcaraz don Pedro Félix Asenjo, quien recibió como dote de sus abuelos paternos casi 4000 reales ${ }^{50}$.

Pero al margen del matrimonio, sería absurdo negar la importancia de las mujeres en la actividad económica del Antiguo Régimen, aunque su vinculación a la vida doméstica ha conllevado que muchas veces se olvide su multiforme participación en la vida laboral ${ }^{51}$. Activas con y sin marido, para muchas, al margen de los escasos ingresos que pudieran obtener de sus reducidas explotaciones con la venta de sus productos (fundamentalmente horticolas y ganaderos) o el recurso a los bienes comunales para el mantenimiento de algunas cabezas de ganado, leña, etcétera, su supervivencia dependería de otras actividades no directamente relacionadas con el campo o de los ingresos derivados de un trabajo asalariado, bien eventual o fijo, tanto propio como de alguno de los miembros de su unidad familiar.

Aunque desgraciadamente para esta zona nada sabemos de forma sistemática sobre las ocupaciones de las mujeres, además de labradoras, en un contexto urbano o semiurbano como el de la ciudad de Alcaraz y por las referencias aisladas que las fuentes nos transmiten, es lógico que también hubiera criadas, panaderas, tenderas, mesoneras, lavanderas, tejedoras, hilanderas, costureras y otra serie de trabajos, en general, poco cualificados y peor retribuidos que formarían parte de esa denominada economía de la improvisación ${ }^{52}$. En este sentido, como actividad complementaria o no, el sector textil sería una de sus principales alternativas productivas respecto de ser muchos los sujetos que tratan en fabricar bayetas (pero también albornoces, estameñas, palmillas, sayales, etc) ${ }^{53}$. Bajo la forma de trabajo a domicilio sobre todo ${ }^{54}$, se trataba de una ocupación donde tradicionalmente se empleaban muchas mujeres, siendo a veces, como ocurría en los núcleos rurales, una dedicación reservada en exclusiva a las mismas: en la pequeña villa de Cotillas se indicaba

50 AHPA, Secc. Protocolos Notariales, Leg. 318, Exp. 1, fol. 125, Escritura de aumento de dote de doña Josefa Asenjo de Vargas (18-12-1769).

s1 Véase por ejemplo las VI Jornadas del Seminario de Estudios de la Mujer sobre El trabajo de las mujeres, siglos XVI-XX (Madrid, UAM, 1987); las Actas de la XXI Settimane di Studi del Instituto Internacional de Historia Económica F. Datini dedicadas a La donna nell'Economia, secc. XII!xvil (Prato, 1990), especialmente los trabajos de Fauve-Chamoux o Palazzi; Trlly, L.-SCott, J. W., (1987); HuffTon, O., (1991); Ferrer I Alós, LL., (1994) o Rial Garcia, S. M., (1995) entre ottos.

52 Término acuñado por Olwen Hufton a mediados de los años 70 . Sobre su potencialidad interpretativa véase por ejemplo CARBonell, M., (1990).

53 AHPA, Secc. 'Catastro del Marqués de la Ensenada, Libro 34, Respuestas Generales de la Ciudad de Alcaraz (véase respuesta número 31 ).

54 Algunos certificados otorgados a varios fabricantes nos dan muestras de ello al señalarse que se habian fabricado en mi casa y con mi propio caudal..... y los llevo a vender (AHPA, Leg. 310, fol. 133-136, julio-agosto de 1755). Igualmente algunos testamentos nos corroboran esta impresión, como el de Angela Niño, de Villapalacios, viuda de Ramón Salvador, que a sus 71 años aún disponía de un telar bien pertrechado para tejer lienzos y pañetes; o el caso ya citado de Beatriz Bermúdez, de Bienservida, que, además del ajuar, dejó a su hija un telar. AHPA, Secc. Protocolos Notariales, Leg. 467, Exp. 11, Testamento de Angela Niño, s. f. (22-X-1830); Leg. 403, Testamento de Beatriz Bermúdez, fol. 32v-34v, (14/7/1781).

Hispunia, LVIl/I, núm. 195 (1997) 115-145 
claramente por no haber hombres que usen y sepan tal oficio al igual que en Bienservida, donde a mediados de la década de los años 80 se decía que con 40 telares se entretienen solo las mugeres; estas surten de estos géneros a este lugar, y a otros muchos ${ }^{55}$. Con dedicación exclusiva o no, lo que es cierto es que en no pocas ocasiones sería la única vía para salir de la indigencia al abrir la posibilidad de que todos los miembros del agregado doméstico pudieran participar en la estructura productiva como se puede deducir de algunos ejemplos como el de Ana María Martínez, viuda de 58 años de la ciudad de Alcaraz que junto a sus dos hijas de 26 y de 24 años se dedicaban a hilar, mientras su hijo de 27 era oficial de zapatero. Actividad además que podía permitir que todos o alguno de los componentes varones se dedicaran a otros trabajos, como ocurría con María Rodenas, igualmente viuda e hilandera, cuyo hijo de 27 años servía como labrador gañán. Y es que para las viudas de avanzada edad, la presencia de un hijo varón en edad de trabajar sería la solución, como ilustra Manuela Romero, viuda de 50 años y vecina de la villa de Bienservida, que tenía dos hijos de 24 y 21 años, significativamente trabajando unas veces en los negocios de la casa y otros en el jornal, auténtico prototipo de pequeña propietaria, a medio camino entre la independencia económica y el recurso al trabajo asalariado ${ }^{56}$.

Se pone de manifiesto, pues, cómo en una zona donde predominaban las pequeñas unidades de producción, campesinas en precario, tejedoras, hilanderas, costureras, etcétera, garantizarían la disponibilidad de una mano de obra barata para cubrir las necesidades de las grandes explotaciones, con las que, sin duda, se establecerían una serie de lazos mucho más complejos que los meramente económicos.

Sus hogares por lo tanto difícilmente se podrían desligar de la gran propiedad, hacia donde inevitablemente debían dirigir sus excedentes laborales, quedando, cómo no, en último extremo el recurso a la emigración ${ }^{57}$. Se comprende así cómo, en función de la necesidad de entrar en el servicio doméstico o de emigrar, muchos de sus hijos permanecerían durante menos tiempo en sus hogares, dando como resultado ese abultado número de agregados solitarios que señalamos al principio.

55 Por su parte, en Cotillas se tejian lienzos y albornoces con ocho telares. Archivo Municipal de Alcaraz, Leg. 488, Exp. 2, «Informe del Estado de las Villas del Partido de Alcaraz que solicita el Rey» (20/Marzo/1747), y respuesta número nueve de las Relaciones del Cardenal Lorenzana correspondientes a la villa de Bienservida (véase la transcripción de las mismas para todo el partido alcaraceño realizada por SANCHEZ GONZÁLEZ, R., (1991:50).

Sh Según el Catastro, con una extensión de 5 hectáreas y media y un producto estimado de 309 reales (de los que 228 correspondían a una sola parcela de 7 celemines de regadio con moreras), más dos pollinas, tres cerdas de cría y otros tres cerdos pequeños, en su casa tenía, además de estos dos hijos, a otra hija y un pariente que eran menores.

57 Así, Rosa María Rodríguez, viuda de 45 años y vecina de Bienservida, tenía, según el Catastro, dos hijos menores trabajando en la hacienda del rico propietario don Gregorio Valero, mientras que otro, de 22 años, también era sirviente fuera del pueblo, como difícijmente podia ser de otra forma si sabemos que no disponia de ningún bien y en su hogar tenía además otra hija menor. 
En concreto, para las mujeres, entrar en el servicio doméstico sería algo habitual entre los 15 y 25 años, es decir hasta el momento de su matrimonio: de 101 criadas contabilizadas en el Catastro para la ciudad de Alcaraz y sus aldeas, 60 estaban en este tramo de edad y 3 por debajo del mismo. Pero para las mujeres viudas o de una determinada edad en absoluto se trataba de una opción descartable en casos de necesidad: entre los 26 y los 60 años encontramos a 27 y con más de sesenta 10. El ejemplo de Antonia Marfa Estero, de la vecina villa de Villanueva de la Fuente es realmente ilustrativo en este sentido. En el año 1738, junto con otros compañeros, su marido Cristóbal García se fue a Murcia en busca de trabajo por la ynopia de los tiempos. Ya no volvería más y hasta su muerte en Buitrago 6 años después no se sabría nada de él. Por ello, viéndose en tan dilatado tiempo sola, pobre y desamparada, viviendo como vivia inmediata a las casas de María Guerrera [que también era viuda] fue llamada para socorrerla y ayudarla en los haceres de su casa por remuneración ${ }^{58}$. Este ejemplo deja entrever también lo importante que podrían llegar a ser las relaciones de vecindad. En este sentido no debemos olvidar que la muerte del marido o de los padres obligaría a reforzar los sistemas de ayuda mutua y adoptar otra serie de medidas estratégicas ante la adversidad. Y aquí sin duda resultaría vital el estrechamiento de los vínculos y de las relaciones de parentesco, plataforma desde la que se podía hacer frente a la nueva situación.

La versatilidad y elasticidad de las redes de parentesco compensaban la fragilidad del sistema económico y demográfico antiguo, convirtiéndose en una de las formas de previsión más practicadas, especialmente por las mujeres, cuyo papel, por otro lado, resultaba clave en su mantenimiento y organización ${ }^{59}$. Así, aunque es cierto que sus relaciones eran más informales, también es cierto que eran más constantes, fluidas e intensas con aquéllos que se consideraban como muy próximos, con aquéllos que se situaban dentro de ese círculo más o menos restringido con el que se convivía y con el que se tenía roce (básicamente parientes pero también vecinos, amigos, etc). No en vano, a las mujeres, consideradas como el eje fundamental en torno al cual giraba la continuidad simbólica de las relaciones familiares por encima del aislamiento o la fragmentación espacial ${ }^{\circ}$, se les ha atribuido un papel de bisagra ${ }^{61}$ que las sitúa en los nudos de las relaciones, en la retícula de la socie-

5R Sus problemas parecian haberse resuelto al entrar a servir con dicha viuda y más con la posibilidad de poder contraer matrimonio con uno de sus hijos al solicitarla de amores con el compromiso de casarse si se confirmaba la muerte de su marido. Después de sus primeras negativas, según sus palabras, se rindió ante tal compromiso. Sin embargo, por el contrario, su situación se complicaria todavía más al quedar embarazada, nacer un niño y no querer casarse con ella. ADA, Vicaria de Alcaraz, Carpeta Villanueva de la Fuente, núm, 3 (sin catalogar). Expediente matrimonial núm. 76, Año 1744.

59 Carbonell, M., (1994).

6) DURÁN, M. A., (1988:16-17). Para un planteamiento más general y en la larga duración de las relaciones intergeneracionales véase Wall, R., (1991).

61 SEGALEN, M., (1992:244).

Hispania, LV][/, núm. 195 (1997) 115-145 
dad civil ${ }^{62}$ a pesar de que su presencia no sea fácilmente perceptible al discurrir por senderos diferentes y expresarse más bien en términos de una verdadera red invisible ${ }^{63}$.

Se pondrían así ahora de manifiesto cómo en muchos casos las fuertes relaciones familiares de apoyo, solidaridad y trabajo vaciarian de contenido tanto la aparente imagen de soledad que, como vimos, reflejaba la estructura demográfica de sus hogares, como de indigencia si nos atenemos estrictamente a la estructura de la propiedad ${ }^{64}$. Manutención y cuidado aunque no se corresidiera ${ }^{65} \mathrm{o}$, incluso, estancias temporales de algunos parientes en su compañía ${ }^{66}$, dan muestra de cómo las paredes del hogar eran en verdad barreras inexistentes, evidenciando a su vez la enorme fluidez entre sus agregados, algo que, en realidad, para una gran parte de las mismas sería el único recurso de la pobreza. Con todo, no todas pudieron acudir a estas ayudas, por lo que en última instancia tuvieron que ser acogidas por instituciones asistenciales o se víeron avocadas al mundo de la mendicidad junto con su prole, situándose, ahora sí, dentro del ámbito de la marginación social.

Pero incluso en estos casos donde las redes de parentesco, amistad o vecindad verían reducida su eficacia por imposibilidad o desavenencias también encontramos muestras de una tremenda desigualdad. Por ejemplo, mientras que Andrea María Gómez o Jerónima Hinglares, solteras, solas y de 40 años, sobrevivirłan gracias a la mendicidad ${ }^{67}$, doña Antonia Teresa Lozano y Maldonado, hermana del que había sido regidor de la ciudad de Alcaraz, don Bal-

62 Comas D'ARgemir, D., (1995:49).

63 WALTERS, M. et al., (1991).

64 Como ha sefralado A. Furió (1991:327-328), los efectos negativos sobre la viabilidad económica de las explotaciones campesinas derivados de una excesiva atomización podian quedar anulados si tenemos en cuenta que la amplia cobertura de la acción familiar integraba a los hogares en un grupo solidario mucho más amplio. A este respecto véase también CHACón JiMÉNEZ, F., (1987:165-166) o GARCIA GONZÁLEZ, F., (1996). En concreto, sobre la importancia de la proximidad geográfica y residencial entre miembros de una misma familia y la enorme movilidad de hijos y parientes entre sus hogares vid. igualmente REHER, D. S. (1984) o GARRIDO ARCE, E., (1992).

65 Como se deduce por ejemplo del testamento de la viuda Angela María, que dejó a su hija un cuarto de casa que colindaba con su propia vivienda por haberla asistido y cuidado «con el cariño que de hija a madre se debe» o del de Beatriz Ramírez, que fue alimentada por su yerno 23 o 24 años, vistiéndola y calzándola, aunque luego a cambio le dejó una casa. Relaciones garantizadas incluso a través de los mecanismos de transmisión de la propiedad, como el caso de Antonia Martinez, que casó en segundas nupcias con Antonio Peláez, a quien en su primer testamento dejaba como heredero universal, pero siempre y cuando durante la vida de su madre se obligara a mantenerla. AHPA, Secc. Protocolos Notariales, Leg. 229, Testamento de Angela Maria, fol. 27-32, (13/6/1721); Leg. 229, Testamento de Beatriz Ramirez, s.f., (5/8/1723); Leg. 403, Testamento de Antonia Martinez, fol. $17 v-19 v,(22 / 6 / 1784)$.

${ }_{66}$ De forma especial sobrinos para ayudarles en las labores y sobre todo sobrinas para asisterles, como de forma expresa seffalaba en su testamento la viuda isabel Sancho. AHPA, Secc. Protocolos Notariales, Leg. 285, Testamento de Isabel Sancho, fol. 103, (21/8/1710).

67 AHPA, Secc. Catastro de la Ensenada, Libro de Personal de la villa de Bienservida, Relaciones 205 y 227 .

Hispanici. LV11/1, núm. 195 (1997) 115-145 
tasar Lozano, no dudó en hacer valer aquéllos bienes que por su prestigio inherente le aseguraban una subsistencia acorde a su posición. De avanzada edad, también soltera y sola tras la muerte de un hermano presbítero con quien había vivido hasta entonces, utilizó los bienes que éste le había legado (fundamentalmente una escribanía en la ciudad) para garantizarse una existencia digna durante el resto de su vida. Así, dejaba como administrador de todas sus propiedades y como heredero universal al escribano don José Rodríguez de Munera con la condición de que pudiera pasarse a vivir a su casa y la mantuviera uen igual forma que a su mujer y hijos, asi estando con salud como en qualesquiera accidentes 68 .

No obstante, si bien la muerte del marido o de los padres para las mujeres solteras tenía unas claras repercusiones sobre todo el entramado de relaciones familiares, también, como contrapartida, la familia ejercería una fuerte presion sobre las mujeres al condicionar seguramente muchas de sus decisiones ${ }^{69}$. Así, aunque a la muerte del marido, la madre como tutora de sus hijos y administradora de sus bienes en la mayoría de las ocasiones asumiera la representatividad legal de la familia y por lo tanto públicamente se reconociera su autonomía, en la práctica ello no siempre sería una realidad. Pero es que además, a la presión familiar habría que añadir la presión social. De hecho, la desaparición del marido conllevaba un trato diferente hacia la viuda, cuya posición en la sociedad estaba claramente determinada por la muerte de aquél ${ }^{70}$, estando sometida desde entonces a un extraordi-

68 Luego sabemos que sólo estuvo una temporada en su casa, dejando después como heredero a Sebastián Romero y estableciéndose un litigio por la posesión de la mencionada escribanía. Su situación se explica porque su hermano regiđor había llevado al matrimonio bienes que superaban con mucho lo que le podía tocar de la herencia de sus padres. Por ello, no habiendo quedado propiedades suficientes para el resto de los hetmanos (otros seis en total) tuvieron que ser mantenidos con las rentas del beneficio que uno de ellos gozaba en la iglesia de Santa María, el licenciado don Lucas Antonio Lozano. AHPA, Secc. Protocolos Notariales, Leg. 302, fol. 54-55. Obligación a favor de doña Antonia Lozano (14-7-1747); Leg. 302, fol. 15-16v. Testamento de doña Antonia Teresa Lozano y Maldonado (2-2-1748).

69 Salvando las distancias, con respecto a las viudas, un caso extremo es el que nos presenta KLAPISCH-ZUBER, C., (1990:251, 256) sobre la Florencia de finales de la Edad Media. En su estudio nos muestra cómo, sobre todo la viuda joven, se convertía en el punto de encuentro donde ferozmente se enfrentaban fuerzas contrapuestas para «disponer de sus cuerpos» y de sus bienes ya que, si bien teóricamente contaban con un cierto margen de elección, en realidad se veian sometidas a presiones contradictorias que le empujaban, más que a vivir independientemente con sus hijos sin volverse a casar, a elegir entre permanecer con la familia de su marido o volver a contraer nupcias y dejar así su primera familia de acogida. De hecho señala que las viudas jóvenes necesitaban una «singular tenacidad y mucho coraje» para resistir dichas presiones. No debemos olvidar, por otro lado, que la mujer estaba mediatizada desde su nacimiento por una socialización familiar que conducia a la asimilación e interiorización de los roles vinculados a su sexo. Ello implicaba aceptar como natural la desigual manera con que debia participar en la producción y en el conjunto de las relaciones sociales.

7 Como señala Molinit-Bertrand, A., (1991:268), a veces se tiene la sensación de que nos movemos en una sociedad donde las viudas y las mujeres solas parece que no existian nada más que en relación al difunto marido, al padre o a un hemano.

Hispania, LV]t/t, núm. 195 (1997) II5-145 
nario y riguroso control social ${ }^{71}$. Su comportamiento debía ajustarse al estereotipo que los moralistas de la época nos trasladaron de la viuda como mujer enlutada, doliente y enclaustrada ${ }^{72}$, y cuyo drama sin embargo ya apuntaba Guevara ${ }^{73}$ en el año 1529 cuando muy acertadamente señalaba que:

si una viuda sale de su casa, la juzgan de deshonesta; si no quiere salir de casa, piérdesele su hacienda; si se rie un poco, nótanla liviana; si nunca se rié, dicen que es hipócrita; si va a la iglesia, nótanla de andariega; si no va a la iglesia, dicen que es a su marido ingrata; si anda mal vestida, nótanla de extremada; si tiene la ropa limpia, dicen que se cansa ya de ser viuda; si es esquiva, notanla de presuntuosa; si es conversable, luego es sospechosa de la casa; finalmente digo, que las desdichadas viudas hallan a mil que juzguen sus vidas, y no hallan uno que remedie sus penas.

\section{CUADRO VII}

MUJER CABEZA DE FAMILIA Y DISTRIBUCION dE LA PROPIEDAD Y LOS CRIADOS EN LA COMARCA DE ALCARAZ (1753)

\begin{tabular}{|c|c|c|c|c|c|}
\hline & DISTRIBUCION & MUJERES & COMARCA & $\%$ MUJER & $\%$ COMARCA \\
\hline \multicolumn{6}{|l|}{ TIERRA } \\
\hline \multirow[t]{9}{*}{ EXTENSION } & $<1$ ha & 65 & 338 & 35.7 & 29.8 \\
\hline & $1-5$ & 36 & 278 & 19.7 & 24.5 \\
\hline & $5-15$ & 44 & 243 & 24.1 & 21.4 \\
\hline & $15-25$ & 19 & 101 & 10.4 & 8.9 \\
\hline & $25-50$ & 10 & 98 & 5.4 & 8.6 \\
\hline & $50-100$ & 3 & 47 & 1.6 & 4.1 \\
\hline & $100-250$ & 4 & 22 & 2.1 & 1.9 \\
\hline & $>250$ & 1 & 8 & 0.5 & 0.7 \\
\hline & TOTAL & 182 & 1135 & 100 & 100 \\
\hline \multicolumn{6}{|l|}{ TIERRA } \\
\hline \multirow[t]{8}{*}{ PRODUCTO } & $<250 \mathrm{rls}$ & 106 & 641 & 58.2 & 56.5 \\
\hline & $250-500$ & 35 & 202 & 19.2 & 17.8 \\
\hline & $500-1000$ & 22 & 147 & 12.0 & 13.0 \\
\hline & $1000-2500$ & 11 & 101 & 6.04 & 8.9 \\
\hline & $2500-5000$ & 5 & 23 & 2.7 & 2.0 \\
\hline & $5000-10000$ & 2 & 12 & 1.09 & 1.1 \\
\hline & $>10000$ & 1 & 6 & 0.5 & 0.5 \\
\hline & TOTAL & 182 & 1135 & 100 & 100 \\
\hline
\end{tabular}

"A este respecto, aunque desde una perspectiva más general, vid. VILLALVA Pérez, E., (1994).

72 VIGIL, M., (1986:195). Sobre la mujer en general y los arquetipos sexistas en el Antiguo

Régimen véase tambièn López-CORDON, M. ${ }^{2}$ V., (1994); REDONDO, A., comp. (1994) o PORRO HERRERA, M. J., (1995) quien nos muestra cómo en las obras literarias los papeles más honorables de la mujeres estaban inevitablemente vinculados a la aceptación de una vida constrentida a los espacios interiores, al sometimiento a reglas preestablecidas y al respeto a modelos de virtud.

73 Citado por ViGIL, M., (1986:202).

Hispania, LVII/I, núm. 195 (1997) 115-145 


\begin{tabular}{|c|c|c|c|c|c|}
\hline & DISTRIBUCION & MUJERES & COMARCA & $\%$ MUJER & $\%$ COMARCA \\
\hline \multicolumn{6}{|l|}{ GANADO } \\
\hline \multirow[t]{7}{*}{ LABOR } & $1 \mathrm{cab}$ & 2 & 40 & 4.3 & 7.8 \\
\hline & 1 par & 21 & 228 & 45.6 & 44.4 \\
\hline & $3-4 \mathrm{cab}$ & 16 & 150 & 34.7 & 29.2 \\
\hline & $5-6 \mathrm{cab}$ & 4 & 63 & 8.6 & 12.3 \\
\hline & $7-8 \mathrm{cab}$ & 1 & 18 & 2.1 & 3.5 \\
\hline & $>8 \mathrm{cab}$ & 2 & 15 & 4.3 & 2.9 \\
\hline & TOTAL & 46 & 514 & 100 & 100 \\
\hline \multicolumn{6}{|l|}{ GANADO } \\
\hline MAYOR & $1-2 \mathrm{cab}$ & 49 & 561 & 41.8 & 49.6 \\
\hline $3-5$ & 25 & 243 & 21.3 & 21.5 & \\
\hline $6-10$ & 26 & 119 & 22.2 & 10.5 & \\
\hline 11.25 & 12 & 82 & 10.2 & 7.3 & \\
\hline $26-50$ & 4 & 21 & 3.4 & 1.9 & \\
\hline $51-100$ & 1 & 17 & 0.8 & 1.5 & \\
\hline$>100$ & 0 & 4 & 0.0 & 0.4 & \\
\hline TOTAL & 117 & 1131 & 100 & 100 & \\
\hline \multicolumn{6}{|l|}{ GANADO } \\
\hline MENOR & $1-5 \mathrm{cab}$ & 70 & 512 & 60.3 & 50.9 \\
\hline 6.25 & 26 & 244 & 22.4 & 24.3 & \\
\hline $26-100$ & 11 & 158 & 9.4 & 15.7 & \\
\hline $101-250$ & 3 & 52 & 2.5 & 5.2 & \\
\hline $251-750$ & 3 & 25 & 2.5 & 2.5 & \\
\hline$>750$ & 3 & 15 & 2.5 & 1.5 & \\
\hline TOTAL & 116 & 1006 & 100 & 100 & \\
\hline \multicolumn{6}{|l|}{ CRIADOS } \\
\hline & 1 & 19 & 180 & 54.2 & 47.9 \\
\hline 2 & 6 & 79 & 17.1 & 21.0 & \\
\hline $3-4$ & 4 & 71 & 11.4 & 18.9 & \\
\hline $5-8$ & 5 & 33 & 14.2 & 8.8 & \\
\hline$>8$ & 1 & 13 & 2.8 & 3.5 & \\
\hline TOTAL & 35 & 376 & 100 & 100 & \\
\hline
\end{tabular}

Fuente: AHPA, Secc. Catastro de la Ensenada, Libros de lo Personal y Libros de lo Real (1753).

\section{BIBLIOGRAFIA}

Alberdi, I., 1988, «Las mujeres viudas y las familias monoparentales», en Las Familias Monoparentales, núm. 5, Ministerio de Asuntos Sociales, Instituto de la Mujer, Madrid., págs. 100-107

Brumont, F., 1984, Campo y campesinos de Castilla la Vieja en tiempos de Felipe II, Madrid, Siglo XXI.

Carasa Soto, P., 1994, "La familia y los grupos populares próximos a la pobreza en la sociedad castellana decimonónica", Boletín de la Asociación de Demografía Histórica, XII, núms. 2-3 (número especial sobre Las economías familiares desde una perspectiva histórica), págs. 253-300.

Hixpania, LVIJ/1, núm. 195 (1997) 115-145 
Carbonell, M., 1990, "Las mujeres pobres en el Setecientos» en Historia Social, núms. 8, Valencia, págs. 123-135.

Carbonell, M., 1994, "Género, pobreza y estrategias de supervivencia. Barcelona, siglo XXvII", Boletín de la Asociación de Demografía Histórica, XII, núm. 2-3 (número especial sobre Las economías familiares desde una perspectiva histórica), págs. 301-316.

Casey, J.- Vincent, B., 1987, "Casa y familia en la Granada del Antiguo Régimen" en Casey, J. et al., La familia en la España mediterránea (siglos $\mathrm{XV}$ $X I X)$,Barcelona, Crítica, págs. 172-211.

Chacón Jiménez, F., 1987, «Notas para el estudio de la familia en la región de Murcia durante el Antiguo Régimen", en La Familia en la España Mediteránea, siglos XV-XIX, Barcelona, Crítica, págs. 129-171.

Chacón Jiménez, F., 1990, Historia social de la familia en España, Instituto Juan Gil Albert, Alicante.

Chacón Jiménez, F. 1995, «Hacia una nueva definición de la estructura social en la España del Antiguo Régimen a través de la familia y las relaciones de parentescon, Historia Social, núm. 21, págs. 75-104.

Chacón, F.-Hernández Franco, J.-Peñafiel, A., eds, 1991, Familia, grupos sociales y mujer en España (siglos XV-XIX), Murcia, Universidad de Murcia.

Chartier, R., 1993a, «Líneas de la Historia Social», Historia Social, núm. 17, otoño, págs. 155-157.

Chartier, R., 1993b, "L'histoire des femmes, xvI-XviII siècle», en Duby,G.Perrot, M., eds, Femmes et histoire, Colloque organisé le 13-14 novembre 1992 en La Sorbonne, París, Plon, págs.39-48.

Comas D'Argemir, M. D., 1995, Trabajo, género, cultura. La construcción de desigualdades entre hombres y mujeres, Barcelona, Institut Català d'Antropologia.

Donezar Díez de Ulzurrum, J. M., 1984, Riqueza y propiedad en Castilla del Antiguo Régimen. La provincia de Toledo en el siglo XVIII, Madrid, MAPA.

Dubert García, I., 1992, Historia de la familia en Galicia durante la epoca moderna (1550-1830). Estructuras, modelos hereditarios y conflictividad, $\mathrm{La}$ Coruña.

Durán, M. ${ }^{a}$ A., 1988, «Hogares y familias: dos conceptos en busca de definición", en Las Familias Monoparentales, Instituto de la Mujer, Serie Debate, núm. 5, págs. 13-22.

Fauve-Chamoux, A., 1981, "La femme seule. Presentation", en Annales de Démographie Historique, págs. 207-213.

Fauve-Chamoux, A., 1990, «Destins de femmes et manufacture textile à Reims avant la révolution industrielle», en La donna nell'economia, secc. XIII-XVII, Instituto Internazionale de Storia Economica F. Datini, Prato, 225-246.

Furio, A., 1991, "Tierra, familia y transmisión de la propiedad en el Pais Valenciano durante la Baja Edad Media», en Reyna Pastor, comp. Relaciones de poder, de producción y parentesco en la Edad Media y Moderma, Madrid, CSIC, págs. 305-328.

Gacto, E., 1987, "El grupo familiar de la Edad Moderna en los territorios del Mediterráneo: una visión jurídica», en La Familia en la España Mediterránea, siglos XV-XIX, Barcelona, Crítica, págs. 36-64. 
García Fernández, M., 1995, Herencia y patrimonio familiar en la Castilla del Antiguo Régimen (1650-1834). Efectos socioeconómicos de la muerte y la partición de bienes, Valladolid, Universidad de Valladolid.

García González, F., 1995, Familia, Propiedad y Reproducción Social en el Antiguo Régimen. La comarca de la Sierra de Alcaraz en el siglo XVII, Cuenca, Universidad de Castilla-La Mancha (micropublicación).

García González, F., 1996, "La continuidad del hogar. Familia, trabajo y mediana propiedad en una economía de montaña del Antiguo Régimen», en Castillo, S., coord.: El trabajo a través de la historia, Madrid, Asociación de Historia Social-UGT, págs. 215-222.

Garrido Arce, E., 1992, "Casa y compañía»: la familia en la Huerta de Valencia, siglo XVIII. Algunas reflexiones teóricas y metodológicas», Boletín de la $A D E H, \mathrm{X}, 3$, págs. 63-82.

Gribaudi, M.-Blum, A., 1990, «Des catégories aux liens individuels: l'analyse statistique de l'espace social", Annales ESC, núm. 6, nov.-déc., págs. 1365 1402.

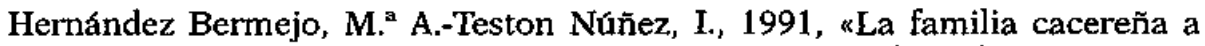
finales del Antiguo Régimen», Studia Historica.Edad Moderna, núm. 9, págs. 143-158.

Hufton, O., 1991, «Le travail et la famille», en Duby, G.-Perrot, M., eds, Histoire des femmes, XVt-XVII siècles, 3, París, págs. 27-57.

Hurtado Martínez, J., 1987, «Familia y propiedad: Análisis del hogar y de la estructura de la propiedad en Lorca (1771)", en Chacón Jiménez, F., ed. Familia y Sociedad en el Mediterráneo Occidental. Siglos XVI-XIX, Murcia, Universidad de Murcia, págs. 301-334.

Izydorczyk-Kamler, A.-Wyczanski, A., 1990, «La femme et l'economie rurale en Pologne aux XVI et XVXII siècles", en La donna nell'economia, secc. XII/$X V H$, Instituto Internazionale de Storia Economica F. Datini, Prato, págs. $275-282$.

Klapisch-Zuber, C., 1990, La Maison et le nom: strategies et rituels dans l'Italie de la Renaissance, CNRS, París.

López-Cordon, M. ${ }^{\mathrm{a}}$ V., 1994, «La conceptualización de las mujeres en el Antiguo Régimen: los arquetipos sexistas", Manuscrits, núm. 12, págs. 79-107.

López Iglesias, F. A., 1987, «Oficios y actividades de las mujeres ovetenses en el Antiguo Régimen», en El trabajo de las mujeres: siglos XVIK-XX, VI Jornadas de Investigación Interdisciplinaria sobre la Mujer, Seminario de Estudios de la Mujer, U.A.M., Madrid, págs. 50-56.

López-Salazar Pérez, J., 1986, Estructuras Agrarias y Sociedad Rural en La Mancha (Siglos XVI-XVII), IEM, Ciudad Real.

Martínez López, D., 1996, Tierra, herencia y matrimonio, Jaen, Universidad de Jaen.

Molinié-Bertrand, A., 1991, «Les veuves dans l'Espagne classique (15501630)", en Carrasco, R., comp., Solidarités et sociabilités en Espagne (XV7-XX siécle), París, Centre de Recherches sur l'Espagne Moderne, pp. 267-275.

Moll Blanes, I., 1987, "La estructura familiar del campesinado de Mallorca, 1824-1827", en Casey, J. et al., La familia en la España mediterránea (siglos $X V-X I X)$, Barcelona, Crítica, págs. 212-257.

Hispania, LVII/1, núm, 195 (1997) 115-145 
Ortega López, M., 1987, «La participación laboral de la mujer en un señorío aragonés durante el siglo XVII: El Señorío de Luna», en El trabajo de las mujeres: siglos $X V I-X X$, VI Jornadas de Investigación Interdisciplinaria sobre la Mujer, Seminario de Estudios de la Mujer, U.A.M., Madrid, págs. 67-76.

Palazzi, M., 1988, "Vivere a compagnia e vivere a dozzina. Gruppi domestici nom coniugali nella Bologna di fine Settecenton, en Ferrante, L.- Palazzi, M.- Pomata, G., comp.: Ragnatele di rapporti. "Patronage» e reti di relazione nella storia delle donna, Torino, págs. 344-380.

Palazzi, M. ,1990, "Tessitrici, serve, treccole". Donne, lavoro e famiglia a Bologna nel Settecento", en La donna nell'economia, secc. XnI-XVHI, Instituto Internazionale de Storia Economica F. Datini, Prato, pp.359-376.

Porro Herrera, M. J., 1995, Mujer "sujeton/mujer "objeto" en la literatura española del siglo de oro, Málaga, Universidad de Málaga.

Redondo, A., comp., 1994, Images de la femme en Espagne aux XVI et XVI siécles, París, La Sorbonne.

Reher, D. S., 1984, «La importancia del análisis dinámico ante el análisis estático del hogar y la familia. Algunos ejemplos de la ciudad de Cuenca en el siglo XIX», en Revista Internacional de Sociologta, núm. 27, págs. 107-135

Reher, D. S., 1994, «Dimensiones del mercado matrimonial en España durante la Restauración», Boletín de la Asociación de Demografía Histórica, XII, núms. 2-3 (número especial sobre Las economías familiares desde una perspectiva histórica), págs. 45-78.

Rial García, S. M., 1995, Las mujeres en la economía urbana del Antiguo Régimen. Santiago durante el siglo XVIII, La Coruña.

Rodríguez Sánchez, A., 1992, “El poder y la familia. Formas de control y consanguinidad en la Extremadura de los tiempos modernos», en Chacón, F. Hernández Franco, J., eds: Poder, familia y consanguinidad en la España del Antiguo Régimen, Barcelona, Anthropos, págs. 15-36.

Sánchez-González, R., 1991, «El partido de Alcaraz a través de las relaciones del cardenal Lorenzana», Al-Basit, núm. 28, págs. 15-75.

Segalen, M., 1992, Antropología histórica de la familia, Madrid, Taurus.

Tilly, L.- Scott, J. W., 1987, Les femmes, le travail et la famille, Marseille, Rivages.

Vigil, M., 1986, La vida de las mujeres en los siglos XVI y XVI, Madrid, Siglo XXI.

Villalva Pérez, E., 1994, "Posibilidades femeninas de vida individual en la España de los Austrias", en Actas del Congreso Historia de la Familia. Una nueva perspectiva sobre la sociedad europea, Murcia, 14-16 de Diciembre (en prensa), págs. 241-252.

Wall, R. , 1991, "Les relations entre générations en Europe autrefois", Annales de Demographie Historique, págs. 133-155.

Walters, M. et al., 1991, La red invisible (Pautas vinculadas al género en las relaciones familiares), Buenos Aires, Paidós.

Woolf, S., 1989, Los pobres en la Europa Moderna, Barcelona, Crítica, págs. 175-217. 